\title{
PATRICIA RODRIGUES LOURENÇO GOMES
}

EFEITO DA EXPOSIÇÃO À DEXAMETASONA SOBRE A EXPRESSÃO DE MIRNA NO PÂNCREAS ENDÓCRINO E A HOMEOSTASIA GLICÊMICA DE RATAS PRENHES

Tese apresentada ao Programa de Pós-Graduação em Fisiologia Humana do Instituto de Ciência Biomédicas da Universidade de São Paulo, para obtenção do Título de Doutor em Ciências. 


\section{PATRICIA RODRIGUES LOURENÇO GOMES}

Efeito da exposição à dexametasona sobre a expressão de miRNA no pâncreas endócrino e a homeostasia glicêmica de ratas prenhes

Tese apresentada ao Programa de Pós-Graduação em Fisiologia Humana do Instituto de Ciências Biomédicas da Universidade de São Paulo, para obtenção do Título de Doutor em Ciências.

Área de concentração: Fisiologia Humana

Orientadora: Profa. Dra. Silvana Auxiliadora Bordin da Silva

Versão original 
DADOS DE CATALOGACLO NA FUBLICACAO ICIP

Senviço de Elbiloteca e informaç5o Blomedica do

inathuto de Clanclas Elomedicas da Universidade de sfo Pasio

inproduçlo nlo actortadie peda aum

Gomes, Patricia Rodrigues Lourenco.

Efelto da exposiça a dexametasona sobre a expressfo de mifNA no pancreas endocrino e a homeostasla gloemica de ratas prenhes / Patricla Rodrigues Lourenço Gomes. - Săo Paulo, 2014.

Orlentador. Profa. Dra. Sllvara Auxlladora Bordin da Silva.

Tese (Doutorado) - Universidade de S3̆o Paulo. Instituto de Clencias Bicmedicas. Departamento de Fislologla e Blofílca. Area de concentraçăo: Fisiologla Humana. LInha de pesquisa: Avallaçăo do pancreas endocrino na gestaçắa.

Versăo do titulo para o ingles: Enect of exposure to dexamethasone on mIFNA expression of the endocrine pancreas and glucose homecstasis of pregnant rats.

1. miRNA 2. Glcocorticoide 3. Gestaça 4. Homeostasla glicemica 5. Celula beta 1. Sliva, Prota. Dra. Silvana Auxlliadora Bordin da il. Unlversidade de Sa Paulo. Institurio de Clenclas Blomedicas.

Programa de Pos-Graduaçăo em Fislologla Humana III. Titulo. 
UNIVERSIDADE DE SÅO PAULO

INSTITUTO DE CIÉNCIAS BIOMÉDICAS

Candidato(a):

Título da Tese:

Orientador(a):
Patricia Rodrigues Lourenço Gomes.

Efeito da exposição à dexametasona sobre a expressão de miRNA no pâncreas endócrino e a homeostasia glicêmica de ratas prenhes.

Profa. Dra. Slvana Auxiliadora Bordin da Silva.

A Comissäo Julgadora dos trabalhos de Defesa da Tese de Doutorado, em sessäo pública realizada a I................, considerou
( ) Aprovado(a)
( ) Reprovado(a)

\begin{abstract}
Examinador(a): Assinatura:
Nome:

Instituiçăo:

Examinador(a): Assinatura:

Nome:

Instituiçăo:

Examinador(a): Assinatura:

Nome:

Instituição:

Examinador(a): Assinatura:

Nome:

Instituiçăo:

Presidente: Assinatura:

Nome:

Instituição:
\end{abstract}


nWwegthant or sin ralan

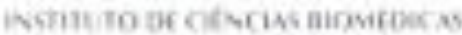

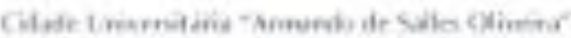

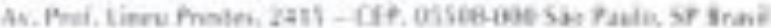

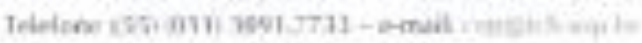

\section{Certificado}

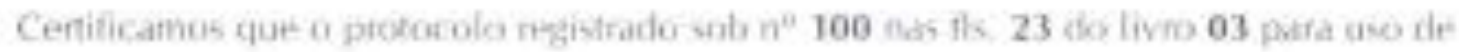
animatis en experimentatais sab a meponsabilidade do Profial Dral Silvana

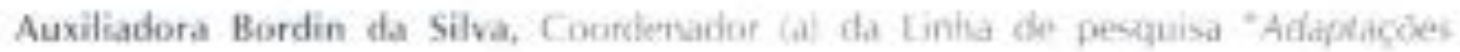

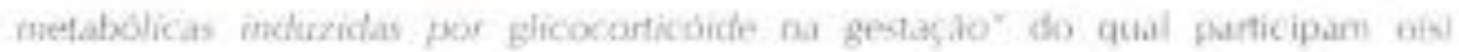
alunosis Patricia Rodrigues Lourenso Gomes, Lucas Carminati Pantaleảo, Sandra

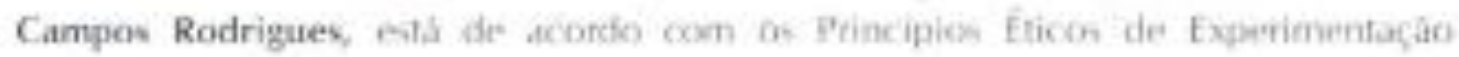
Animal adotado pela Soriedade Brasaleira de Ciência de Anamais de Labocatortio

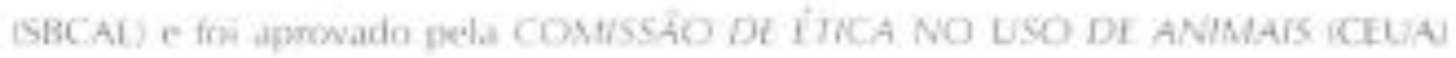
am 10.11.2014, com validade de 4 anos.

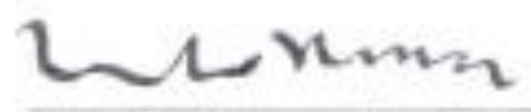

Prot Dr. Wrathas Tayakes or Lima Coondernadon. CTLIA- ICBALST

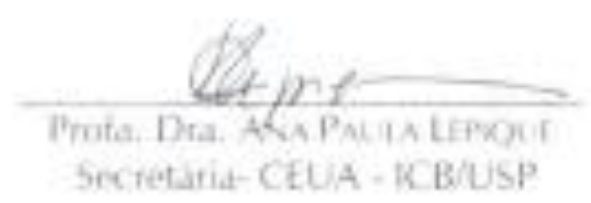


Dedico este trabalho e todos os anos que aqui passei aos meus pais (Edson e Maria) e à minha irmã (Gabriela), por sempre entenderem os momentos em que não pude estar por perto e pelo apoio incansável e incessante. Vocês sonharam o mesmo sonho que eu e hoje ele se torna realidade, dou a vocês esse título. 


\section{AGRADECIMENTOS}

Meus sinceros votos de agradecimento:

À minha querida orientadora Prof ${ }^{\mathrm{a}}$. Dr ${ }^{\mathrm{a}}$. Silvana Bordin, por toda a confiança em mim depositada, pelos momentos de aprendizado, por toda a paciência e ensinamentos tão valiosos que contribuíram para minha formação e para minha carreira científica de modo íntegro e profissional como forma de criação e melhorias para a vida humana.

Às minhas queridas professoras e ex-orientadoras Prof ${ }^{\mathbf{a}}$. Dr ${ }^{\mathbf{a}}$. Edna Maria do Carmo e Prof ${ }^{a}$. Dra . Patrícia Monteiro Seraphim, que me conduziram da graduação para a vida acadêmica. Não me esquecerei do caminho percorrido com vocês e do carinho materno que recebo até hoje.

Aos meus pais Edson e Maria, pelos esforços nunca medidos para garantir minha educação e, acima de tudo, meus sonhos. Mais uma vez sem palavras suficientes espero agradecer de modo justo, à altura de toda a batalha e paciência a mim dedicada. Minha mãe, cuidadora do lar para que todos nós tivéssemos um lugar para descansar a alma. Meu pai, homem de caráter moldado no trabalho pesado, pensando em dar às filhas as oportunidades que não teve. Vocês são o alicerce da minha vida e da minha coragem.

À minha irmã Gabriela pela companhia de sempre, pelas risadas e por todas as conversas e momentos que farão nossas vidas estarem ligadas para sempre, porque você faz parte de mim e sempre será o elo mais forte com o meu passado e a companhia mais certa no meu futuro. "You are my person!"

Ao meu querido companheiro Cristiano Rocha da Silva pela imensa paciência durante o tempo de elaboração desta tese, pelo estímulo, pelo carinho, pelo convívio e pelas inúmeras contribuições profissionais e pessoais tornando possível entender como superar a mim mesma.

Às minhas queridas amigas Fernanda G Amaral, Chayrra C Gomes e Adriana R Leite. Tenho eterna gratidão por vocês que tornaram meus dias mais leves e felizes, principalmente nos momentos difíceis de adaptação à nova casa. 
Aos velhos amigos do GPFis, Ana Carolina P Costa, Bruna B Brandão, Rafael J Moreira e Danilo C P Jr. pela amizade sincera de muitos anos. Não importa a distância e as ocupações da vida, a gargalhada do reencontro é sempre certa.

Ao amigo José Maria Rodrigues Júnior gostaria de agradecer pelo tempo dedicado a mim para a execução de todos os trâmites burocráticos envolvidos com a pós-graduação, além disso, pelas horas que passamos contando experiências de vida. Você é um funcionário e ser humano exemplar.

À FAPESP pelo apoio financeiro. 
"A cada dia que vivo mais me convenço de que o desperdício da vida está no amor que não damos, nas forças que não usamos, na prudência egoísta que nada arrisca e que, esquivandonos do sofrimento, perdemos também a felicidade." 


\section{RESUMO}

Gomes PRL. Efeito da exposição à dexametasona sobre a expressão de miRNA no pâncreas endócrino e a homeostasia glicêmica de ratas prenhes. [tese (Doutorado em Fisiologia Humana)]. São Paulo: Instituto de Ciências Biomédicas, Universidade de São Paulo; 2014.

Numerosos estudos têm-se centrado sobre a programação metabólica induzida pelo excesso de glicocorticoide gestacional, com especial atenção para os mecanismos que levam ao aparecimento de diversas doenças e até reprogramação gênica na prole. No entanto, o impacto pelo excesso de glicocorticoide durante a gestação sobre o metabolismo materno não está bem documentado. Portanto, este estudo investigou se o tratamento com glicocorticoide sintético durante a gestação altera o metabolismo energético, hormonal e molecular materno e a função das ilhotas pancreáticas e mudanças correlativas sobre miRNAs e seus alvos. Para isto foram utilizadas 80 ratas dividas em dois grupos de 40 animais cada, sendo um grupo destinado para realização de GTT, ITT e envelhecimento até um ano de idade após o desmame, e o seguinte grupo destinado para realização da coleta de material e posterior experimentação no $20^{\circ}$ dia de gestação. Ambos os grupos foram dispostos em: CTL - ratas controle, CTL-Dex - ratas controle tratadas com dexametasona por 6 dias, P - ratas prenhes e, P-Dex - ratas prenhes tratadas com dexametasona do $14^{\circ}$ ao $19^{\circ}$ dia de gestação. As ilhotas pancreáticas foram coletadas para análise em larga escala da expressão de miRNA e a família do miR-29 foi selecionada para estudo posterior. Os genes alvos foram rastreados em bancos de dados e confirmados por PCR em tempo real. Por fim investigou-se o mecanismo de modulação da homeostasia glicêmica por meio de PCR em tempo real e Western Blotting. O perfil do miR29 observado no grupo P-Dex imediatamente após o tratamento permaneceu um ano após o desmame da prole. A análise de mRNA do mesmo tecido mostrou modulação significativa nos genes p53, PUMA e Stx-1 no grupo P-Dex tanto no $20^{\circ}$ dia de gestação como um ano após o desmame da prole. Além dessas alterações, foi observada intolerância à glicose no grupo P-Dex no desmame, no $3^{\circ}$ e $6^{\circ}$ mês e um ano após o desmame da prole; contudo, não foi observada resistência à insulina nos mesmos períodos. A secreção de insulina de ilhotas coletas no $20^{\circ}$ dia de gestação não apresentou alterações. Por outro lado, um ano após o desmame foi possível observar que ilhotas do grupo P-Dex só responderam ao teste em altas concentrações de glicose. Por fim, observaram-se significativas alterações no receptor de progesterona e proteínas envolvidas na remodelação das ilhotas pancreáticas responsáveis pelo retorno ao estado não gravídico. Assim é possível observar inúmeras modificações resultantes da terapia com DEXA na gestação concluindo que a associação do tratamento ao período gravídico modula positivamente membros da família miRNA-29 ocasionando um desequilíbrio na homeostasia glicêmica por meio de falha na maquinaria exocitótica em longo prazo, desencadeado pela modulação negativa de progesterona e seu receptor promovendo prejuízo no processo de remodelação da ilhota pancreática na fase final da gestação.

Palavras-Chave: miRNA. Glicocorticoide. Gestação. Homeostasia Glicêmica. Célula Beta. 


\begin{abstract}
$\mathcal{A B S T \mathcal { T A C T }}$
Gomes PRL. Efeito da exposição à dexametasona sobre a expressão de miRNA no pâncreas endócrino e a homeostasia glicêmica de ratas prenhes. [PhD Thesis (Human Physiology)]. São Paulo: Instituto de Ciências Biomédicas, Universidade de São Paulo; 2014.
\end{abstract}

Several studies have focused on the metabolic programming in pregnancy induced glucocorticoid excess, with special attention to the mechanisms that lead to the onset of various diseases and even genetic reprogramming in offspring. However, the impact by glucocorticoid excess during pregnancy on the maternal metabolism is not well documented. Therefore, this study investigated whether treatment with synthetic glucocorticoids during pregnancy alters the energetic, hormonal and molecular maternal metabolism and function of pancreatic islets and correlative changes of miRNAs and their targets. For this were used 80 rats divided into two groups of 40 animals each, one group designed to perform GTT, ITT and aging up to one year of age after weaning, and the next group destined to collect the materials and later experimentation the $20^{\text {th }}$ day of gestation. Both groups were arranged: CTL - control rats, CTL-Dex - control rats treated with dexamethasone for 6 days, P - pregnant rats and PDex - pregnant rats treated with dexamethasone from the $14^{\text {th }}$ to $19^{\text {th }}$ day of gestation. The pancreatic islets were collected for large-scale analysis of miRNA expression and the miR29's family was selected for further study. The target genes were screened in databases and confirmed by real-time PCR. Finally it was investigated the mechanism of modulation of glucose homeostasis through real-time PCR and Western Blotting. The profile of miR-29 observed in P-Dex group immediately after treatment remained one year after weaning of the offspring. Analysis of mRNA from the same tissue showed significant modulation of p53, PUMA and Stx-1genes in P-Dex group both on day 20 of gestation as one year after weaning of the offspring. In addition to these changes was observed glucose intolerance in P-Dex group at weaning, at $3^{\text {rd }}$ and $6^{\text {th }}$ months and one year after weaning of offspring, however, resistance to insulin was not observed in the same periods. Insulin secretion of islets collected on the $20^{\text {th }}$ day of gestation showed no changes. On the other hand, one year after weaning was observed that the P-Dex group responded to the test at high glucose concentrations. Finally, were observed significant changes in progesterone receptor and proteins involved in the remodeling of pancreatic islets responsible for returning at non pregnant state. Therefore can be observed numerous changes resulting from therapy with DEXA in pregnancy concluded that the association of treatment to the pregnancy period modulates members of the miRNA-29 family causing an imbalance in glucose homeostasis through long-term failure in exocytotic machinery, triggered by the downregulation of the progesterone and its receptor promoting injury in the pancreatic islet remodeling process in late pregnancy.

Keywords: miRNA. Glucocorticoid. Pregnancy. Glucose Homeostasis. Beta Cell. 


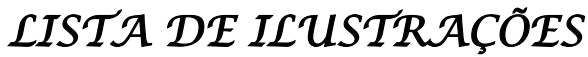

Figura 1. Ilustração demonstrativa do mecanismo de formação e maturação do miRNA ........ 20

Figura 2. Esquema demonstrativo do tempo e modelo de experimentação ............................. 28

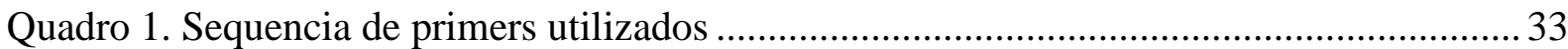

Figura 3. Evolução do peso corporal do $14^{\circ}$ dia de gestação até o final da lactação, glicemia matutina antes e durante o tratamento com DEXA, tolerância à glicose no dia seguinte do

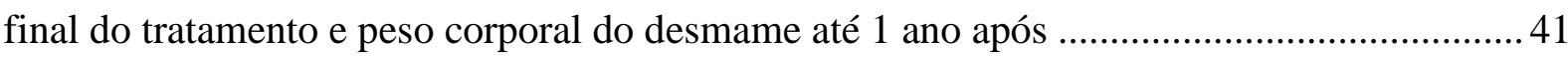

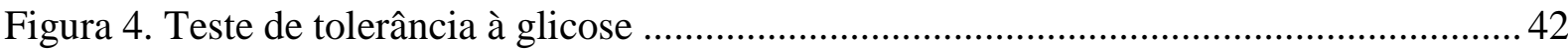

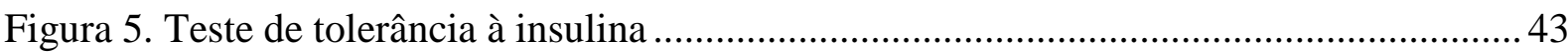

Figura 6. Secreção estática de insulina estimulada por glicose no $20^{\circ}$ dia de gestação e um ano

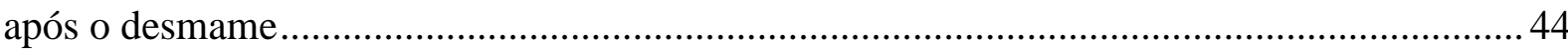

Figura 7. Detecção imuno-histoquímica de insulina no pâncreas em G20 ............................ 45

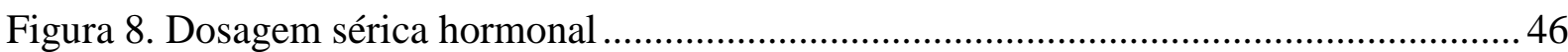

Figura 9. Expressão dos miRNA miR-29a, miR-29b e miR-29c .......................................... 48

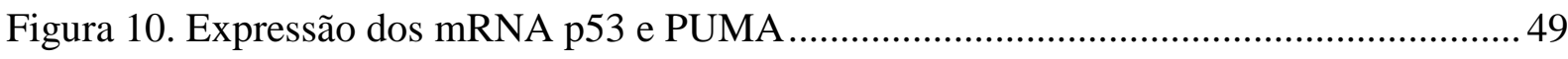

Figura 10.1Conteúdo proteico de p53 e Sintaxina-1a ........................................................... 50

Figura 11. Detecção por imuno-fluorescência de insulina e granulócito .................................51

Figura 12. Conteúdo proteico de pJNK, pIKK, pIKB, IKB e NFkB e expressão gênica de NFkB 52

Figura 13. Expressão gênica e conteúdo proteico do receptor de progesterona(PR) 53 


\section{LISTA DE ABREVIATURAS E SIGLAS}

BSA: bovine serum albumin (albumina sérica bovina)

cDNA:complementary deoxyribonucleic acid (ácido desoxirribonucleico complementar)

CEUA: Comissão de ética no uso de animais

CTL: grupo controle

CTL-Dex: grupo controle tratado com dexametasona

DAB: diaminobenzidina

DEXA: dexametasona

DG: diabetes gestacional

dL: decilitro

DM2: diabetes mellitus tipo 2

DNA:deoxyribonucleic acid (ácido desoxirribonucleico)

EDTA: Ethylenediamine tetraacetic acid(ácido etilenodiamino tetra-acético)

g: grama

G20: $20^{\circ}$ dia de gestação

GC: glicocorticoide

GR: glucocorticoid receptor(receptor de glicocorticoide)

GTT: glucose tolerance test(teste de tolerância à glicose)

ITT: insulin tolerance test (teste de tolerância à insulina)

Kg: kilogramas

M: molar

miRNA: micro ribonucleic acid (micro ácido ribonucléico)

mRNA: messenger ribonucleic acid (ácido ribonucléico mensageiro)

mg: microgramas

$\mathrm{mL}$ : microlitro

mM: micro molar

ng: nanograma

nm: nanômetro 
P: grupo de ratas prenhes

PBS: phosphate buffered saline (tampão fosfato-salino)

PCR: polymerase chain reaction (reação em cadeia da polimerase)

P-Dex: grupo de ratas prenhes tratadas com dexametasona

pg: picograma

qPCR: quantitative polymerase chain reaction (reação em cadeia da polimerase em tempo real)

RNA: ribonucleic acid (ácido ribonucléico)

rpm: rotações por minuto

SBCAL: Sociedade Brasileira de Ciências de Animais de Laboratório

SDS: sodium dodecil sulfate (dodecilsulfato de sódio)

TAE: tampão Tris-Acetato-EDTA

UA: unidades arbitrárias

UV: ultra violeta

$\mu \mathrm{L}:$ microlitro

$\mu \mathrm{g}$ : micrograma

$\mu \mathrm{m}$ : micrômetro

${ }^{\circ} \mathrm{C}$ : graus Celsius 
LISTA DE SÍMBOLOS

$\%$ : porcentagem

$\beta$ : beta

(®): registrado

TM: trade mark 


\section{SUMMÁRIO}

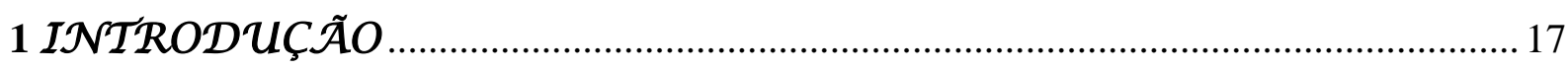

1.1 Adaptação metabólica durante a gestação e a lactação …......................................... 18

1.2 Adaptação do pâncreas endócrino no final da gestação e no início da lactação ........ 18

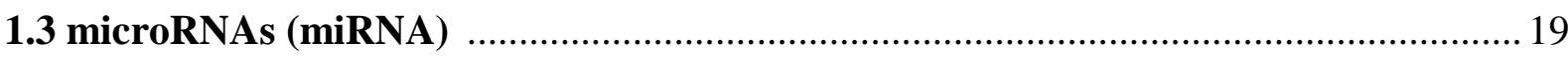

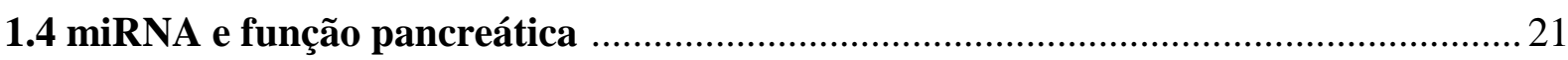

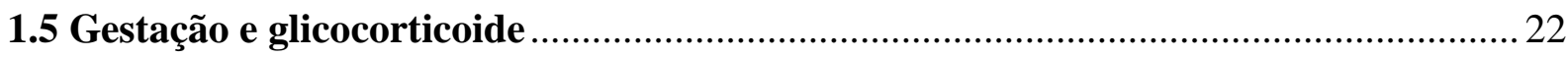

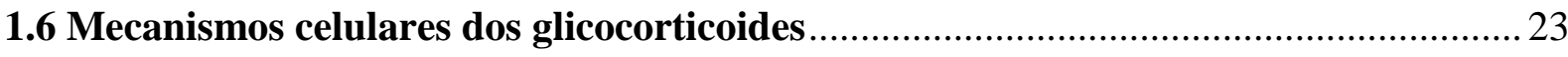

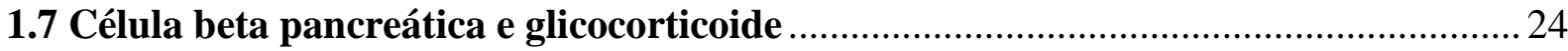

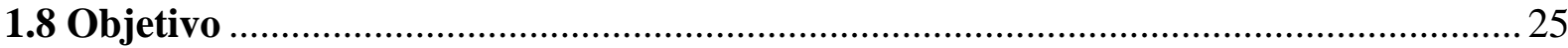

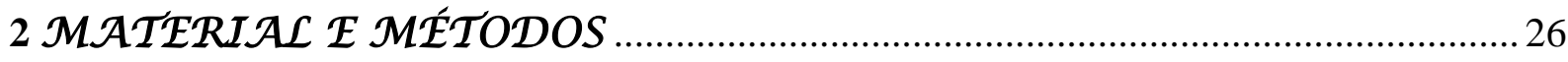

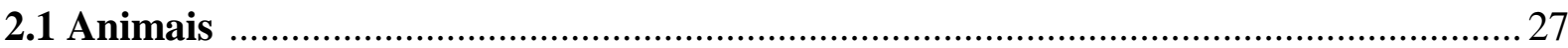

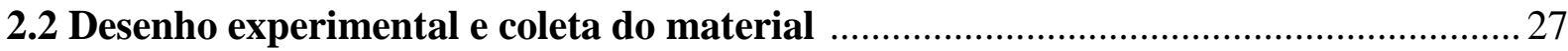

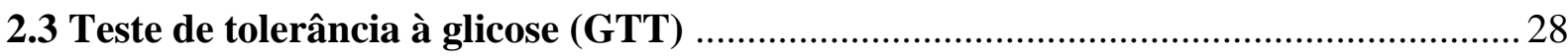

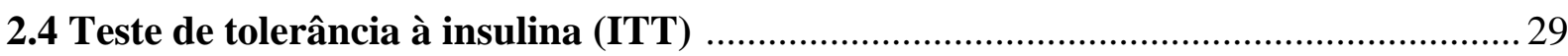

2.5 Isolamento das ilhotas pancreáticas (método da colagenase) ....................................29

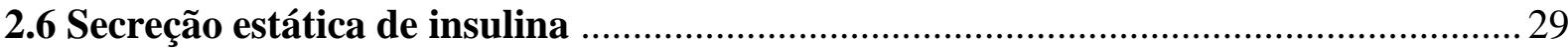

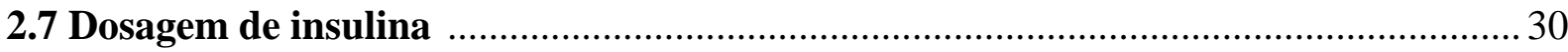

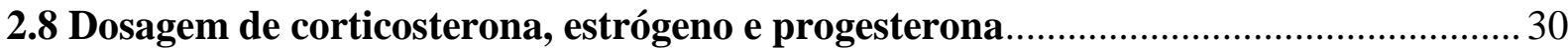

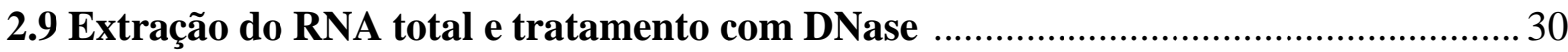

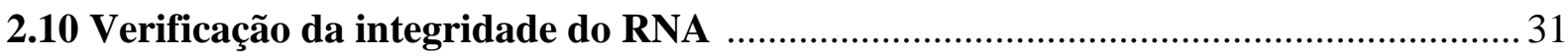

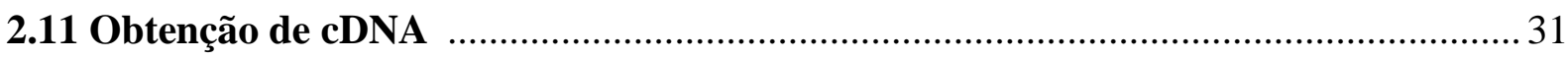

2.12 Análise do perfil da expressão de miRNAs em larga escala - miRNA PCR array . 32

2.13 Análise quantitativa da expressão dos mRNAs/miRNAs por reação em cadeia da

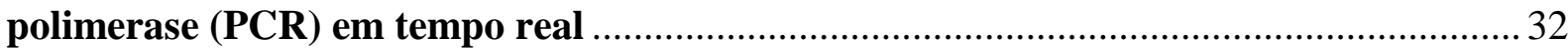

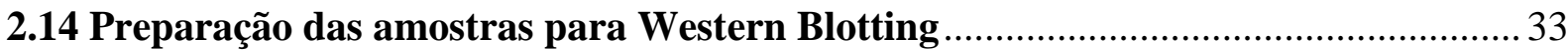

2.15 Método breadford para dosagem de proteínas - protein assay ............................... 34

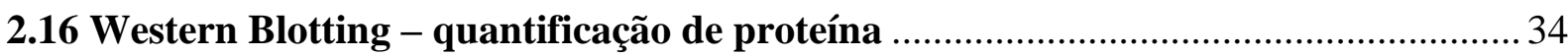

2.16.1 Eletroforese em gel de poliacrilamida (SDS - PAGE) ............................................. 34

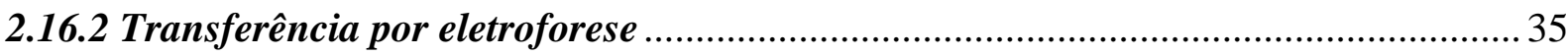

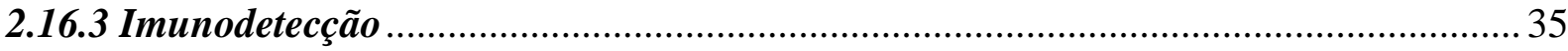

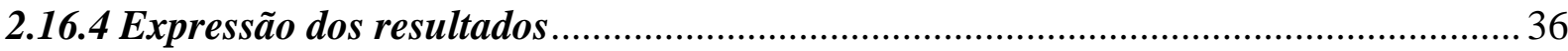

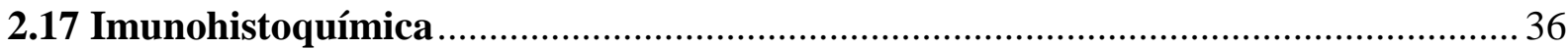


2.18 Imunofluorescência

2.19 Análise dos dados

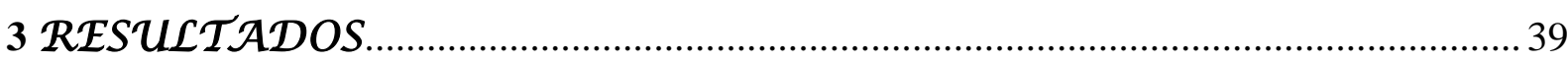

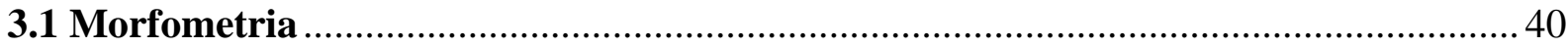

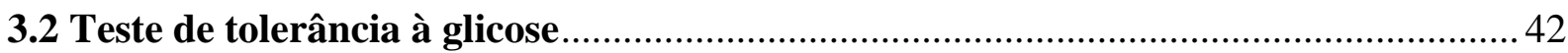

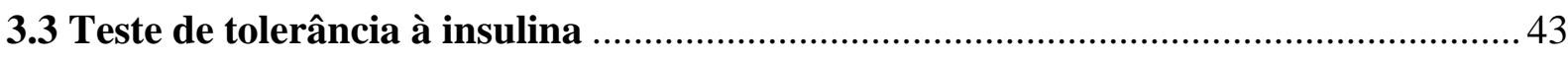

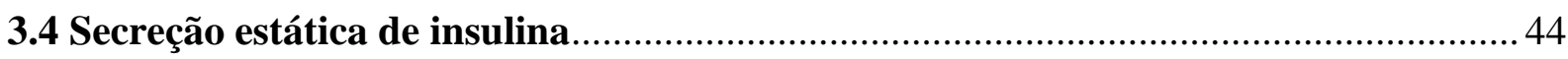

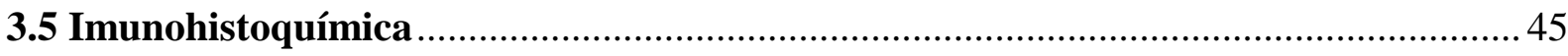

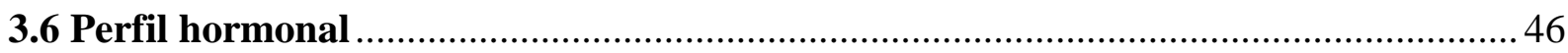

3.7 Análise da expressão dos miRNAs por PCR em tempo real ..................................... 47

3.8 Análise da expressão dos mRNAs alvos por PCR em tempo reale quantificação proteica por Imunoblotting de p53, PUMA e Stx-1.

3.9 Análise de mecanismos desencadeadores da perda tardia da função pancreática de ratas tratadas com DEXA durante $03^{\mathbf{0}}$ período gestacional ......................................... 50

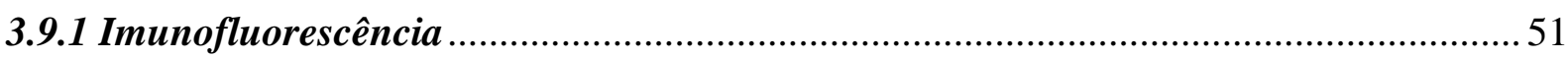

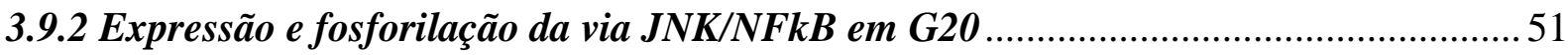

3.10 Análise da expressão dos mRNAs por PCR em tempo real e quantificação proteica

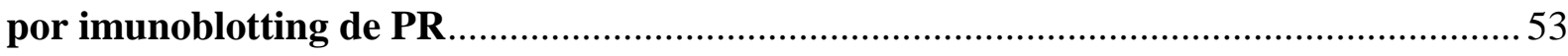

4 DISCUSS ÃO

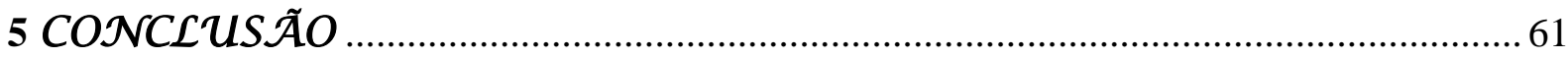

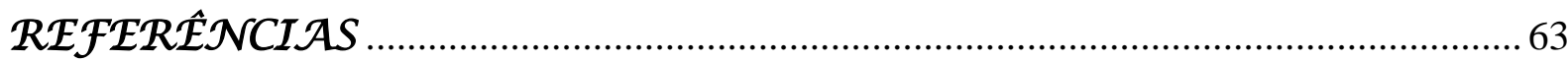

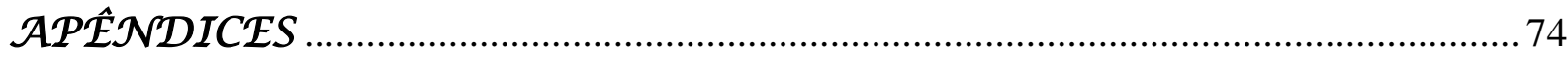

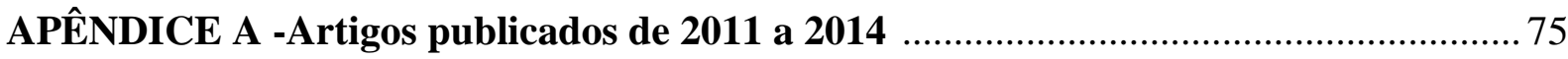

APÊNDICE B -Artigo submetido para publicação (em revisão) ................................... 76 


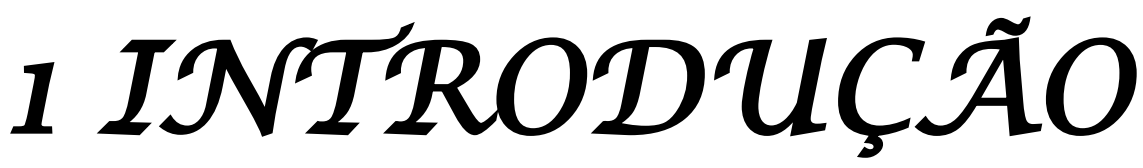




\subsection{Adaptação metabólica durante a gestação e a lactação}

A gestação é um período caracterizado por alterações que resultam em um quadro semelhante à síndrome metabólica, mas que geralmente são cuidadosamente reguladas para fornecer suprimento ideal de substratos para a mãe e para o feto. Observa-se no final da gestação de ratas aumento na taxa de utilização de glicose pelo concepto representando cerca de $23 \%$ do total utilizado pelo organismo materno. Além disso, em resposta ao estímulo pela insulina, a placenta ainda demonstra um aumento adicional de $30 \%$ na utilização de glicose ${ }^{1}$.

Este fluxo representativo de glicose direcionado ao concepto é garantido pela resistência à ação da insulina no tecido adiposo e na musculatura esquelética ${ }^{1,2}$. Quando levados em consideração todos os tecidos responsivos à insulina, a captação de glicose diminui de 40 a $60 \%$ durante uma gestação normal, tanto em humanos como em roedores ${ }^{3,4}$. Sabe-se que aumentos nas concentrações plasmáticas materna de esteróides sexuais, prolactina, lactogênio placentário e corticosteróides estão relacionados às alterações acima descritas 5 .

Certamente a placenta, uma fonte de estrógenos, progesterona, lactogênio placentário e gonadotrofina coriônica, é o órgão que desempenha o papel principal nestas alterações ${ }^{6}$. Além destes hormônios, a unidade feto-placentária produz e secreta, entre outros, hormônios como leptina $^{7}$, resistina ${ }^{8}$, hormônio do crescimento ${ }^{9}$, fatores de crescimento semelhante à insulina I e II (IGFI e II) ${ }^{10}$ e hormônio liberador de corticotrofina ${ }^{11}$. Desta maneira o desenvolvimento da unidade feto-placentária desencadeia a produção e a liberação para a corrente sanguínea de hormônios que, salvo situações não fisiológicas, são produzidos em territórios bem definidos do organismo materno. Este fato torna complexa a origem das alterações maternas que se relacionam ao controle da homeostasia glicêmica durante a gestação e a lactação.

\subsection{Adaptação do pâncreas endócrino no final da gestação e no início da lactação}

Em meados do século passado já se observava a expansão do volume das ilhotas durante a gravidez, resultado do aumento da proliferação de células beta com redução da apoptose $^{3-6}$. Em roedores, esse aumento inicia-se ao redor do décimo dia de gestação, com pico ao redor do décimo quarto dia. Em paralelo a proliferação, ocorre o aumento da síntese e secreção de insulina, esta última decorrente da redução do limiar de sensibilidade à glicose ${ }^{7}$. 
Porém, da mesma forma que a massa e atividade do pâncreas endócrino aumentam durante a gravidez, ocorre involução do tecido após o parto ${ }^{4}$. As primeiras evidências na literatura mostram que (1) a involução está correlacionada ao aumento da expressão do TGF $\beta 1$, um marcador associado ao processo de apoptose na célula beta ${ }^{6}$ e (2) a dexametasona (DEXA) contrapõe os efeitos mitogênicos observados tanto no tratamento "in vitro" com prolactina como na gravidez ${ }^{8}$. Neste último, os autores propõem que o aumento dos níveis plasmáticos de glicocorticoides no final da gestação são os responsáveis pela reversão dos efeitos estimulatórios induzidos pela prolactina, inibindo a secreção de insulina, a proliferação celular e estimulando a apoptose.

Um painel mais detalhado dos mecanismos envolvidos no remodelamento funcional da ilhota pancreática durante a transição gestação-lactação tem sido desenhado a partir dos estudos realizados pelo nosso grupo. Demonstramos que a redução da secreção após o parto está associada (1) à redução da expressão de Serca2 mediada pelo fator de transcrição STAT3 $^{12}$, e (2) ao aumento da expressão da proteína G inibitória Rasd1, que depende da associação entre STAT5 - o sinalizador intracelular clássico da prolactina - e o receptor de glicocorticóide $^{13}$. Com relação à regulação de massa de célula beta, mostramos pela primeira vez a ativação do estresse do reticulo endoplasmático em um modelo fisiológico de remodelamento tecidual ${ }^{14}$, bem como a participação dos glicocorticoides na regulação negativa dos sinalizadores intracelulares mitogênicos ERK1 e ERK2 ${ }^{15}$.

\section{3 microRNAs (miRNA)}

Os genes codificadores de proteínas são geralmente regulados pela expressão de outras proteínas e/ou fatores de transcrição que agem como reguladores à jusante do gene. Os recentes avanços da elucidação dos mecanismos de regulação da informação genética póstranscricional ganharam impulso a partir do descobrimento dos microRNA (miRNA).

O primeiro miRNA foi descoberto em 1993 por meio de rastreamento genético de mutações em Caenorhabditis elegans ${ }^{16}$. Desde então, o uso de novas técnicas de análise de expressão em larga escala, bem como de melhores ferramentas computacionais, permitiram um entendimento mais amplo da função dos miRNA no desenvolvimento normal humano e na doença. miRNA são moléculas de RNA de fita simples com cerca de18 a 22 nucleotídeos, conhecidas por regular negativamente a expressão no nível pós-transcricional, tanto pela inibição da tradução quanto pela indução da degradação do mRNA alvo ${ }^{17,18}$. A Figura 1 
apresenta uma ilustração demonstrativa do mecanismo de maturação do miRNA, desde o surgimento no núcleo até a execução de sua função.

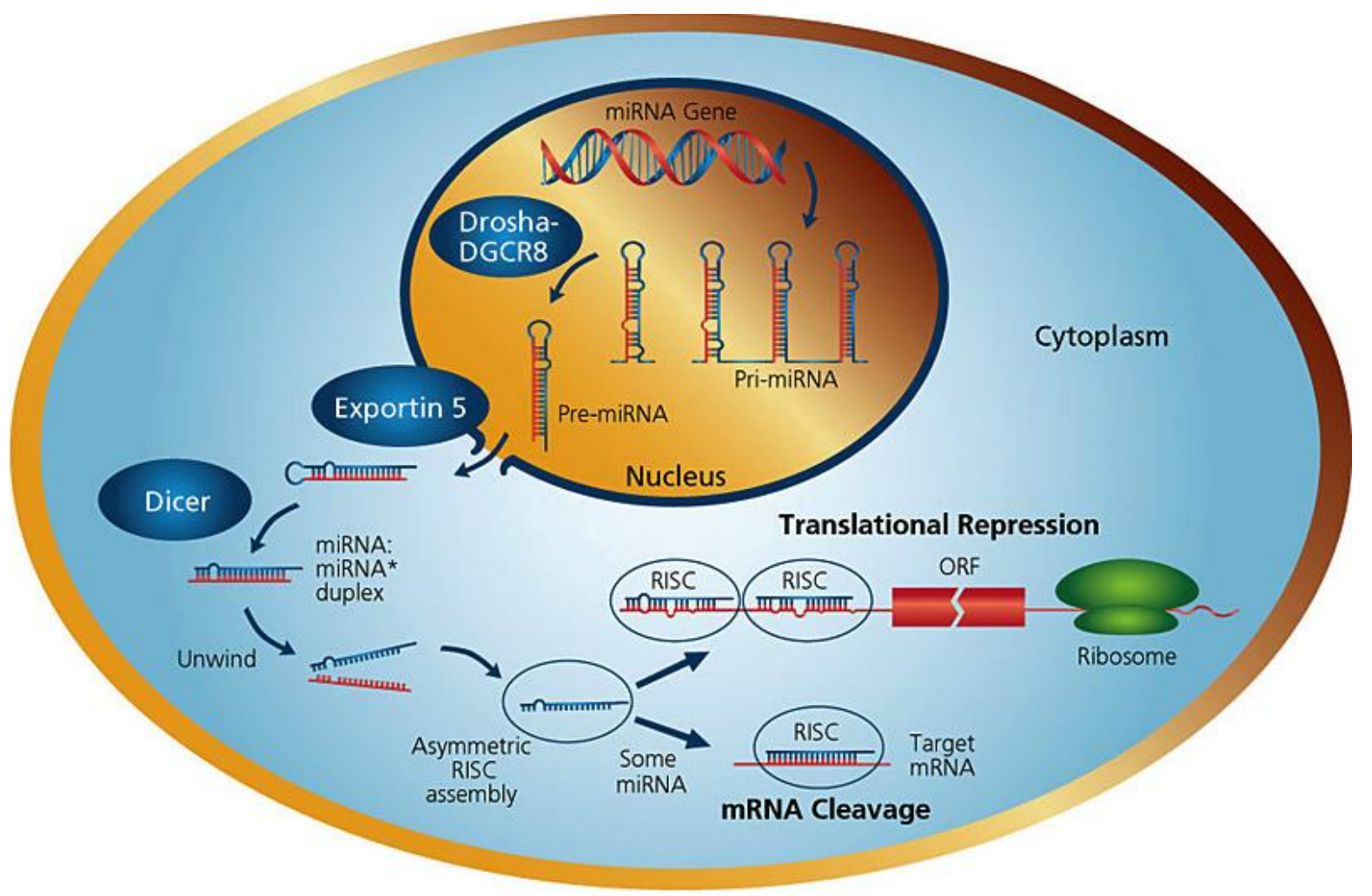

Figura 1. Ilustração demonstrativa do mecanismo de formação e maturação do miRNA ${ }^{19}$.

Várias centenas de genes codificadores dos miRNA já foram identificados por métodos computacionais, e alguns deles validados funcionalmente. A função exata da maioria dos miRNA ainda permanece desconhecida; entretanto, há evidências da participação em processos tão diversos quanto o desenvolvimento embrionário ${ }^{20}$, a manutenção de células tronco $^{21}$, a resposta ao estresse ${ }^{22}$, a neurodegeneração ${ }^{23}$, a resistência viral ${ }^{24}$, a apoptose ${ }^{25}$ e a secreção hormonal $^{26}$.

De forma geral, os miRNA de mamíferos regulam a estabilidade e/ou eficiência da tradução dos transcritos de seus genes-alvos pela ligação à região 3' não-traduzida (3'-UTR). Acredita-se que o genoma humano possui mais de 1000 miRNA potenciais ${ }^{27}$, e que $30 \%$ de todos os genes transcritos sejam regulados por miRNA ${ }^{28}$. Embora centenas de miRNA já tenham sido identificados em várias espécies de mamíferos, a caracterização dos alvos funcionais tem sido uma tarefa desafiadora. Isto se deve ao fato de que, nos mamíferos, cada miRNA pode potencialmente regular mais de 200 transcritos diferentes, e o mesmo gene pode ser regulado por diferentes miRNA. Entretanto, genes alvos de miRNA caracterizados podem 
ser rastreados utilizando-se ferramentas computacionais de domínio público disponíveis em banco de dados, por exemplo,miRBase ${ }^{29}$, que contém um repertório atualizado de miRNA e permite a busca de genes alvos candidatos utilizando programas como TargetScan (MIT), Pictar (NYU e MDC-Berlin) e miRanda (MSKCC).Das várias centenas de miRNA identificadas, apenas uma parcela foi validada experimentalmente ${ }^{30}$.Além dos achados obtidos nas diversas áreas que já tem consistentemente estudado a participação dos miRNA nos processos biológicos - como a embriologia, a neurobiologia e a oncologia -, evidências recentes indicam que os miRNA têm importância central na regulação dos eventos moleculares envolvidos na patogênese do Diabetes Mellitus.

\section{4 miRNA e função pancreática}

A participação dos miRNA no metabolismo energético foi inicialmente aventada após a demonstração da regulação do metabolismo lipídico pelo miR-14 ${ }^{16}$. Deste então, vários estudos têm demonstrado a função de miRNA em todos os órgãos relacionados direta ou indiretamente ao metabolismo da glicose, como ilhotas pancreáticas, fígado, músculo esquelético, tecido adiposo e sistema nervoso central.

O primeiro estudo conduzido em células de insulinoma (MIN6) revelou 67 miRNA expressos em células beta, dentre as quais miR-375 foi identificado como o miRNA mais abundante e aparentemente específico da ilhota pancreática. Os eventos pelos quais a secreção de insulina é modificada pelo miR-375 são independentes de alterações no metabolismo da glicose ou da modulação do $\mathrm{Ca}^{2+}$ intracelular, mas tem correlação direta com a exocitose dos grânulos de insulina ${ }^{31}$. Oknockdown da proteína miotropina (Mtpn) identificada e validada como alvo do miR-375 - mimetizou os efeitos da superexpressão do miR-375 sobre a secreção de insulina estimulada por glicose, demonstrando assim pela primeira vez a participação de um miRNA na regulação do processo secretor. É interessante ressaltar que o miR-375, juntamente com vários outros miRNA, parecem ter função importante no desenvolvimento pancreático ${ }^{32}$.

Estudos subsequentes mostraram que outros miRNA são importantes para o processo de exocitose: (a) miR-9 regula a secreção de insulina por diminuição da expressão do fator de transcrição Onecut-2 que, por sua vez ativa a granulofilina/Slp4, um regulador negativo da secreção $^{33}$; (b) miR-96 aumenta o mRNA e o conteúdo proteico de granulofilina, um modulador negativo da exocitose de insulina, e diminui a expressão Noc2, resultando em menor capacidade das células MIN6 em responder ao secretagogos; (c) miR-124a aumenta a 
expressão de SNAP25, Rab3A e sinapsina-1a, e diminuição de Rab27A e Noc2 ${ }^{34}$; (d) o fator de transcrição FoxA2, que regula a expressão de genes específicos da célula beta como Pdx-1, Kir6.2 e Sur-1, também já foi validado como gene-alvo do miR-124a ${ }^{32}$.

Tanto a glicose quanto os ácidos graxos induzem alterações na expressão de miRNA. Em 2009,Tang e colaboradores mostraram que de um total de 108 miRNA rastreados, 61 se mostraram responsivos à glicose ${ }^{35}$. Dentre os miRNA regulados positivamente por altas concentrações de glicose encontram-se miR-124a, miR-107 e miR-30d; a expressão de miR296, miR-484, e miR-690 foi significativamente diminuída pelo mesmo tratamento. A superexpressão de miR-30d aumentou a transcrição do gene da insulina induzida por glicose, mas não a secreção, o que sugere que miR-30d é importante para a regulação negativa de um repressor transcricional da expressão do gene da insulina. Em um estudo mais amplo, Hennessy, 2010 ${ }^{36}$, identificaram 21 novos miRNA em células MIN6, desconhecidos até o momento. Além disto, foi comparado o perfil de células MIN6 responsivas à glicose com o de células MIN6 não responsivas. Um conjunto de 10 miRNA apresentou expressão suprimida em células MIN6 não responsivas, quando comparados os perfis entre os dois fenótipos. Análises funcionais mostraram que parte destes miRNA (miR-200a, miR-130a e miR-410) diminui a capacidade secretora destas células em resposta à glicose.

Em um estudo utilizando o tratamento crônico com palmitato, conhecido fator associado ao Diabetes Mellitus do tipo 2 (DM2), observou-se que a exposição de células MIN6 ou ilhotas isoladas a ácidos graxos causou o aumento da expressão de miR-34a e miR146. O aumento da expressão de ambos miRNA se mostrou associado à sensibilidade à apoptose, enquanto que apenas o miR-34a parece estar envolvido no processo de secreção, mediada pela regulação direta da proteína VAMP $2^{37}$.Em células NIT-1, uma linhagem de células beta derivadas de camundongos NOD, a expressão do miR-375 esta associada à maior susceptibilidade a lipoapoptose induzida por palmitato ${ }^{38}$. É importante destacar que a expressão destes miRNA foi alterada apenas pelo tratamento crônico (48-72h). Este fenômeno tardio pode explicar as diferenças entre os efeitos agudo (aumento de secreção) e crônico (redução da secreção) dos ácidos graxos, e sugere que outros agentes com efeitos similares podem ser mediados por miRNA.

\subsection{Gestação e glicocorticoide}

Os glicocorticoides (GC), como o cortisol nos seres humanos e corticosterona em roedores, são produzidos no córtex adrenal, e desempenham um papel fundamental na 
regulação da homeostase da glicose e metabolismo dos nutrientes. Glicocorticoides sintéticos, como a dexametasona, são amplamente prescritos na prática clínica devido as suas propriedades anti-inflamatória, antialérgica, e imunossupressora, são também o tratamento padrão para a asma, artrite reumatóide, lúpus eritematoso sistêmico e inflamatório doenças intestinais $^{39,40}$, além da proteção contra a rejeição de órgão transplantado ${ }^{38}$. Entretanto, os níveis supra fisiológicos (endógenos ou exógenos) induzem efeitos adversos relacionados à homeostase da glicose, como a diminuição da sensibilidade periférica à insulina, intolerância à glicose e dislipidemia ${ }^{41-44}$. Além disso, dependendo do perfil genético, idade, tempo e dose da exposição, pode também levar ao aparecimento de DM2 ${ }^{42,44-49}$.Estes efeitos secundários são observados particularmente em indivíduos susceptíveis, como gestantes, obesos, pessoas com resistência à insulina ou parentes de primeiro grau de pacientes diabéticos ${ }^{50}$.

A regulação metabólica materna durante a gravidez é um fator importante que afeta o crescimento e desenvolvimento fetal. A gravidez é caracterizada por um estado de resistência à insulina no final da gestação, o que é essencial para proporcionar substratos para o feto em desenvolvimento, enquanto há uma diminuição natural na sensibilidade à insulina, podendo levar ao quadro de Diabetes Gestacional (DG). Em todo o mundo 3-10\% das gestações são complicadas por controle glicêmico anormal, causada principalmente pelo diabetes gestacional $^{51}$.

DG resulta em exposição do feto ao aumento das concentrações de glicose no plasma como resultado do aumento da transferência placentária, bem como aumento da secreção de insulina através da atividade do pâncreas fetal em resposta às concentrações de glicose no plasma fetal. A exposição ao DG pode alterar o transporte de glicose fetal devido a modificações na expressão do transportador de glicose por solutofacilitado 2 (SLC2A), que é expresso no pulmão ${ }^{52}$. Além disso, a insulina desempenha um papel importante no desenvolvimento deste órgão ${ }^{53}$, e os seus efeitos são mediados pela sinalização de IGF, incluindo IGF-1, IGF-2 e do receptor (IGF-1R).

\subsection{Mecanismos celulares dos glicocorticoides}

Noventa e cinco por cento do cortisol circulante está ligado às globulinas e albumina ${ }^{54}$, os níveis séricos da forma inativa são de aproximadamente 50-100 nM, e o hormônio é em grande parte não ligado a proteínas do plasma. A conversão entre as formas ativas e inativas é catalisada pela 11beta-desidrogenase (11beta-HSD), uma redutase que converte cortisona (em seres humanos) e 11-desidrocorticosterona (em roedores) em cortisol e corticosterona, 
respectivamente ${ }^{55,56}$. A isoforma do tipo 2 funciona como uma desidrogenase que catalisa a reação oposta ${ }^{57}$.

As ações de 11beta-HSD1 e 11beta-HSD2 servem como um controle pré-receptor de ação do GC e determina as concentrações locais. A ação local de GC nas células é ativada pelo hormônio esteroide ao seu receptor (GR), um fator de transcrição regulado pelo ligando que pertence à superfamília de receptores nucleares, liga-se ao GC e regula a transcrição de genes alvo através da ativação ou da repressão ${ }^{58}$.

O GR é expresso em quase todos os tecidos, no entanto, é capaz de regular os genes de uma forma específica, indicando que a resposta aos GCs é regulada por fatores além da expressão do receptor. O receptor é guiado a partir da síntese para se decompor por meio de transdução de sinal e por uma variedade de chaperonas moleculares, tais como HSP70 ${ }^{59}$ e $\mathrm{HSP}^{60}{ }^{60}$, que facilitam o dobramento, a maturação e a ligação do ligando. Além disso, a ativação da transcrição mediada pelo GR é modulada tanto positivamente quanto negativamente por fosforilação ${ }^{61}$ realizado por quinases e fosfatases.

Embora a atividade do GR seja frequentemente considerada em termos de transativação direta de genes, considerável cross-talk ocorre também entre o GR e um grupo de moléculas que medeiam a sua função como fatores de transcrição, incluindo os octâmerosOut1, Out2, CREB (AMPc proteína de ligação do elemento) e Stat5 (transdutores de sinal e ativadores de transcrição-5 $)^{62-64}$.

\subsection{Célula beta pancreática e glicocorticoide}

Em resposta a resistência à insulina periférica induzida por GC e na tentativa de manter a normoglicemia, as células beta pancreáticas sofrem várias adaptações morfofuncionais que resultam em hiperinsulinemia. A falha das células beta para compensar esta situação favorece perturbações da homeostase da glicose, o que pode resultar em hiperglicemia. O tratamento com GC não só altera a função destas células, células alfatambém são afetadas por ações de GC que podem levar a hiperglucagonemia, contribuindo para o desequilíbrio da homeostase da glicose e hiperglicemia. Além disso, a liberação de outros hormônios das ilhotas, como a somatostatina, amilina e grelina, também são afetados ${ }^{65}$.

O principal mecanismo pelo qual as células beta geram hiperinsulinemia durante a compensação adaptativa consistem em compensações funcionais (o aumento da biossíntese de insulina e/ou de secreção) e adaptações estruturais (hiperplasia, aumento no número de células 
beta e hipertrofia que pode resultar em aumento da massa de células beta ${ }^{66-68}$.Assim, quandonão há mecanismos compensação, um processo de glicolipotoxicidade desenvolve-se progressivamente induzindo morte celular acompanhada por hipoinsulinemia, hiperglicemia e hiperlipidemia ${ }^{67}$.

\subsection{Objetivo}

Numerosos estudos têm-se centrado sobre a programação metabólica induzida pelo excesso de glicocorticoide gestacional, com especial atenção para os mecanismos que levam ao aparecimento tardio da síndrome metabólica na prole. No entanto, o impacto pelo excesso de glicocorticoide durante a gestação sobre o metabolismo materno não está bem documentado. Portanto, este estudo investigou se o tratamento com glicocorticoide sintético durante a gestação altera o metabolismo energético, hormonal e molecular materno, em especial à função das ilhotas pancreáticas. Além disso, procurou-se também mudanças correlativas sobre miRNAs e seus alvos, particularmente aqueles que desempenham papel chave na função do pâncreas endócrino. 


\section{$2 \mathcal{M} \mathcal{A} \mathcal{T} \mathcal{R} I \mathcal{A} \mathcal{E}$ MÉTODOS}




\subsection{Animais}

Foram utilizadas oitenta ratas Wistar, virgens, com dois meses de idade, fornecidas pelo Biotério Central da Universidade de São Paulo e, mantidas no Biotério do Departamento de Fisiologia e Biofísica da mesma instituição, à temperatura média de $22 \pm 2{ }^{\circ} \mathrm{C}$, com ciclos de 12 horas de luminosidade, sendo das 07h00min as 19h00min horas (período claro) e 19h00min as 07h00min (período escuro).

Após 15 dias de adaptação à troca de ambiente os animais foram alocados em gaiolas plásticas coletivas, na disposição de duas ratas e um rato para o acasalamento. A gravidez foi confirmada por esfregaço vaginal, sendo a fecundação considerada no dia em que houve detecção de espermatozoide na fase estro do ciclo ovulatório. Após o acasalamento as ratas foram dispostas em caixas coletivas de cinco animais de acordo com a separação por grupo e, a partir do $14^{\circ}$ dia de gestação todos os animais foram alocados individualmente até o início do procedimento experimental.

O estudo foi aprovado pela Comissão de Ética no Uso de Animais (CEUA), protocolo nº100 fls 23 no livro 03, e obedece aos "Princípios Éticos na Experimentação Animal", adotado pela Sociedade Brasileira de Ciência de Animais de Laboratório (SBCAL).

\subsection{Desenho experimental e coleta do material}

Primeiramente foram separados dois grupos de quarenta animais cada, sendo um grupo destinado à realização de GTT, ITT, envelhecimento até um ano após o desmame e posterior experimentação, e o seguinte grupo para a realização da coleta de material e posterior experimentação no $20^{\circ}$ dia de gestação (G20). Para tanto, ambos os grupos foram dispostos da seguinte maneira:

CTL: grupo controle, dez ratas não prenhes e não tratadas.

CTL-Dex: grupo controle tratado, dez ratas não prenhes submetidas à ingestão de água com DEXA por seis dias.

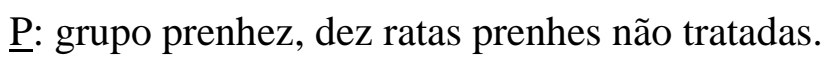

P-Dex: grupo prenhez tratado, dez ratas prenhes submetidas à ingestão de água com DEXA do $14^{\circ}$ ao $19^{\circ}$ dia de prenhez.

Os grupos CTL-Dex e P-Dex receberam DEXA na água de beber em concentrações de $0,5 \mathrm{mg} / 5 \mathrm{ml}$, equivalentes a $0,2 \mathrm{mg} / \mathrm{kg} / \mathrm{dia}$. Os grupos de animais destinados à realização de GTT e ITT foram submetidos ao experimento nos seguintes períodos: $21^{\circ}$ dia de lactação 
(desmame), um mês, dois, três e seis meses e um ano após o desmame da prole. Após completarem 20 dias de gestação e um ano após o desmame da prole (aproximadamente 15 meses de vida) os animais foram narcoseados com $\mathrm{CO}_{2}$ e eutanaseados por decapitação para remoção do pâncreas. Subsequentemente os tecidos foram identificados para posterior isolamento das ilhotas pelo método da colagenase.

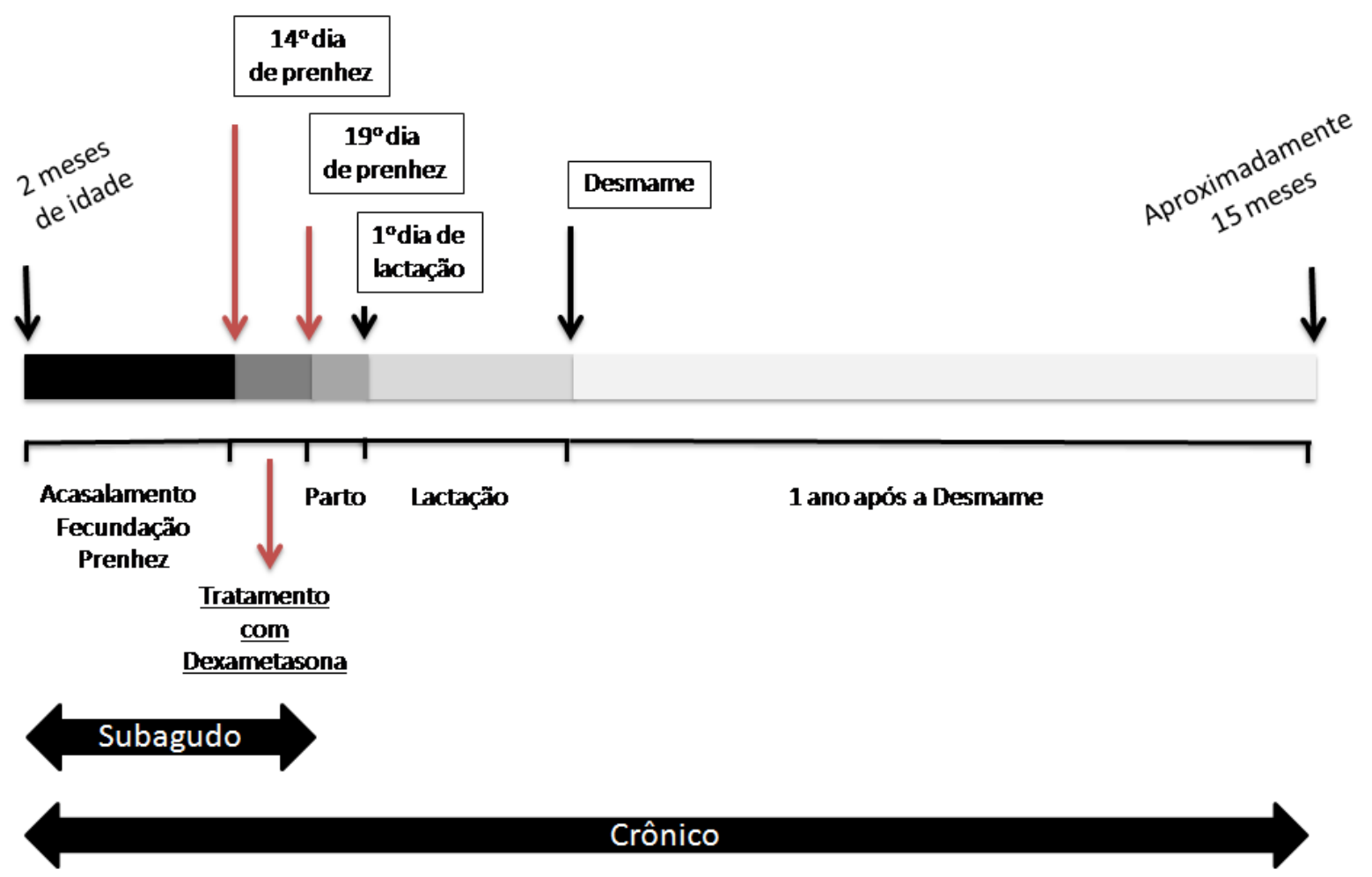

Figura 2. Esquema demonstrativo do tempo e modelo de experimentação.

\subsection{Teste de tolerância à glicose (GTT)}

O teste foi realizado nos períodos supracitados e consistiu na administração de glicose $20 \%$, via intraperitoneal, ao longo de 120 minutos na proporção de $1,5 \mathrm{~g}$ glicose $/ \mathrm{kg}$ de animal. As amostras de sangue foram coletadas antes da aplicação de glicose e a 5, 10, 15, 30, 60 e 120 minutos após a aplicação. Foi realizada uma pequena secção na extremidade distal da cauda do animal e a glicemia foi mensurada com medidor manual de glicemia (Accu-Chek Active / Roche ${ }^{\circledR}$ Diagnostics / Mannheim - Alemanha). 


\subsection{Teste de tolerância à insulina (ITT)}

O teste foi realizado nos mesmos períodos do GTT e consistiu na administração de $2 \mathrm{U}$ de insulina regular/kg de peso, via intraperitoneal, ao longo de 30 minutos. As amostras de sangue foram coletadas antes da aplicação de insulina e a 5, 10, 15 e 30 minutos após a aplicação. Foi realizada uma pequena secção na extremidade distal da cauda do animal e a glicemia foi mensurada com medidor manual de glicemia (Accu-Chek - Active / Roche ${ }^{\circledR}$ Diagnostics / Mannheim - Alemanha).

\subsection{Isolamento das ilhotas pancreáticas (método da colagenase)}

O animal narcoseado e decapitado foi submetido a uma incisão abdominal para localização do ducto pancreático e obstrução em sua porção distal e, em seguida um pequeno orifício foi aberto próximo à região hepática. O pâncreas foi perfundido com $15 \mathrm{~mL}$ de solução de Hanks enriquecida com colagenase $(0,7 \mathrm{mg}$ de colagenase / $\mathrm{mL}$ de Hanks a 5,6 $\mathrm{mM}$ de glicose).

Após a perfusão o tecido foi retirado, transferido para uma placa de Petri onde foi limpo eliminando gorduras, linfonodos e vasos sanguíneos maiores e, em seguida colocado em um tubo Falcon para digestão com colagenase a $37^{\circ} \mathrm{C}$ por 25 minutos, sem agitação. Após incubação foi adicionado solução de Hanks gelada até completar o volume de $30 \mathrm{~mL}$ e o tubo foi agitado vigorosamente por um minuto, a seguir o preparado foi lavado com a mesma solução quatro vezes para retirada da suspensão ${ }^{12,15,69}$. O material precipitado foi então distribuído em placas de Petri para coleta de ilhotas sob lupa, com auxílio de pipeta de vidro estirada. Por fim, as ilhotas coletadas foram utilizadas para posterior experimentação.

\subsection{Secreção estática de insulina}

Para a avaliação da secreção estática de insulina foram utilizados grupos de cinco ilhotas em triplicata para cada condição experimental. As amostras foram pré-incubadas durante 30 minutos em Krebs-Henseleit contendo 0,2\% de albumina em 5,6 mM glicose e incubadas em $500 \mu \mathrm{L}$ durante 1 hora em 5.6, 8.3, 11.1 ou $16.7 \mathrm{mM}$ glicose em $0,2 \%$ de albumina permanecendo em banho a $37^{\circ} \mathrm{C}$. Após o período de incubação de 1 hora, $300 \mu \mathrm{L}$ do sobrenadante foi removido e estocado a $-20{ }^{\circ} \mathrm{C}$ para posterior dosagem de insulina por radioimunoensaio. 


\subsection{Dosagem de insulina}

A determinação da quantidade de insulina secretada foi determinada por radioimunoensaio. Para tanto, a solução reagente incluiu uma quantidade conhecida de anticorpo, uma quantidade conhecida do hormônio marcado radioativamente (insulina marcada com iodo ${ }^{125} \mathrm{I}$, Amershan Biosciences, Inglaterra) e uma quantidade desconhecida de hormônio não radioativo (amostra). Como as duas formas do hormônio, radioativos e não radioativos, competem por um mesmo número de sítios de ligação ao anticorpo, quanto mais hormônio não radioativo estiver presente, menos o hormônio radioativo irá se ligar. O complexo insulina-anticorpo marcado formado foi precipitado em polietilenoglicol (PM 6000) e dosado em contador tipo gama (PerkinElmer, Turku, Finlândia). Uma curva padrão foi preparada, na qual a relação ligado/livre para o hormônio radioativo foi plotada como função da concentração do hormônio não radioativo. A relação ligado/livre do hormônio radioativo é maior quanto menor concentração da insulina não radioativa estiver presente. A seguir, a curva padrão foi utilizada para determinar a concentração do hormônio em cada amostra. Os resultados foram expressos em $\mathrm{ng} / \mathrm{ml}$ da solução de incubação das 5 ilhotas.

\subsection{Dosagem de corticosterona, estrógeno e progesterona}

A quantificação das concentrações plasmáticas de corticosterona, estrógeno e progesterona foram realizados por meio de ensaio imunoenzimático (ELISA) conforme especificações do fabricante (Corticosterona: Neogen, Lexington, KY; Estrógeno e Progesterona: Immunotech, France).

\subsection{Extração do RNA total e tratamento com DNase}

As ilhotas foram homogeneizadas com Trizol Reagent ${ }^{\circledR}$ (Invitrogen) conforme especificação do fabricante, para obtenção do RNA total. A análise da concentração e pureza do RNA total foi mensurada por espectrofotometria utilizando o aparelho NanoDrop ${ }^{\mathrm{TM}} 1000$ (Thermo Scientific, Wilmington, DE, EUA), nos comprimentos de onda de 260 e $280 \mathrm{~nm}$ para determinação da concentração (ng / $\mu \mathrm{L}$ ) e da razão 260/280, que é um indicativo de qualidade do RNA extraído.

Para eliminar eventual contaminação com DNA genômico, as amostras de RNA total foram tratadas com Turbo DNA-free ${ }^{\mathrm{TM}}$ (Ambion, Austin, TX, EUA) de acordo com as 
especificações do fabricante. As amostras foram mantidas à $-80^{\circ} \mathrm{C}$ para posterior síntese de cDNA.

\subsection{Verificação da integridade do RNA}

Para verificar a integridade do RNA total extraído das ilhotas foi preparado um gel de agarose a $1 \%$ submerso em tampão de corrida TAE $1 \mathrm{x}$, em cada poço do gel foi adicionado 1 $\mu \mathrm{L}$ de amostra acrescido de $0,5 \mu \mathrm{L}$ de Blue Green Loading Dye I (LGC Biotecnologia, Cotia, $\mathrm{SP}$ - Brasil) e 3,5 $\mu \mathrm{L}$ de $\mathrm{H}_{2} \mathrm{O}$ MiliQ. Em seguida o gel foi submetido à eletroforese $(80 \mathrm{~V}, 400$ $\mathrm{mA}$, por aproximadamente 45 minutos) e, posteriormente verificado sob luz ultra violeta (UV) observando a presença e qualidade de duas bandas (28s e 18s) na proporção de 1,5/1. As imagens foram obtidas através do sistema de fotografia UV transluminador BenchTop 3UV ${ }^{\mathrm{TM}}$ (BioDoc - It ${ }^{\mathrm{TM}}$ Imaging System, CA, EUA)

\subsection{Obtenção de cDNA}

Este procedimento envolveu a obtenção de cDNA a partir dos miRNAs contidos nas amostras de RNA total extraídos. Para tanto foi necessário realização de duas etapas: (1) poliadenilação dos miRNA, e (2) transcrição reversa dos miRNA.

Na etapa 1 do procedimento, $2 \mu \mathrm{g}$ de RNA total, na concentração de $260 \mathrm{ng} / \mu \mathrm{L}$, foram submetidos à reação de poliadenilação utilizando $1 \mu \mathrm{L}$ de tampão da Poly(A) polimerase10x, $1 \mu \mathrm{L}$ trifosfato de adenosina, $0,5 \mu \mathrm{L}$ da enzima E.Coli Poly(A) Polimerase (BioLabs ${ }_{\text {Inc., }}$, New England) e 5,5 $\mu \mathrm{L}$ de $\mathrm{H}_{2} \mathrm{O}$ MiliQ. A mistura foi incubada por 10 minutos à $37{ }^{\circ} \mathrm{C}$, e posteriormente a cada amostra foi acrescido $0,5 \mu \mathrm{L}$ de adaptador ( 5' GGC CAC GCG TCG ACT AGT ACT TTT TT 3', $\mathrm{TM}=64,2^{\circ} \mathrm{C}$, diluído para $10 \mu \mathrm{M}$ ) e novamente incubadas por 5 minutos à $60^{\circ} \mathrm{C}$ e por 2 minutos à $25^{\circ} \mathrm{C}$. Em seguida as amostras foram resfriadas a $4{ }^{\circ} \mathrm{C}$ para realização da etapa 2 que consistiu em acrescentar $9,5 \mu \mathrm{L}$ da mistura para transcrição reversa que continha $4 \mu \mathrm{L}$ de tampão da enzima (50 nM de Tris- $\mathrm{HCl} \mathrm{pH}$ 8,3, $75 \mathrm{mM}$ de $\mathrm{KCl}, 3 \mathrm{mM}$ de $\mathrm{MgCl}_{2}$ ), 3,5 $\mu \mathrm{L}$ de de $\mathrm{MgCl}_{2}, 1 \mu \mathrm{L}$ de dNTPs e $1 \mu \mathrm{L}$ da enzima Improm-II ${ }^{\mathrm{TM}}$ Reverse Transcriptase (Promega Corporation, WI, EUA), em volume final de $20 \mu \mathrm{L}$. As reações foram incubadas em termociclador por 5 minutos à $25^{\circ} \mathrm{C}$ para anelamento, seguida de 60 minutos à $42{ }^{\circ} \mathrm{C}$ para extensão e 15 minutos à $70^{\circ} \mathrm{C}$ para inativação da enzima. As amostras de cDNA foram armazenadas à $-20^{\circ} \mathrm{C}$. 
Para obtenção de cDNA a partir do mRNA contidos nas amostras de RNA total extraídos, que foram posteriormente utilizados para análise quantitativa por qPCR é necessário a realização apenas da etapa 2 descrita acima.

\subsection{Análise do perfil da expressão de miRNAs em larga escala - miRNA PCR array}

Após a etapa de transcrição reversa já descrita seguiu-se para análise em larga escala da expressão dos miRNAs. Para isso foi utilizado o kit miRNome microRNA Profilers QuantiMir $^{T \mathrm{M}}$ (System Biociences - SBI, North Shoreline, Mountain View, CA) em placa de 384 poços contendo primers para miRNAs anotados no Sanger miRBASE, os primers foram ressuspensos em $20 \mu \mathrm{L}$ de $\mathrm{H}_{2} \mathrm{O}$ MiliQ antes de iniciar o procedimento.

Posteriormente foi adicionado a placa um mix contendo $1250 \mu \mathrm{L}$ de SYBR Green $2 \mathrm{x}$ qPCR Mastermix buffer, $50 \mu \mathrm{L}$ de primer reverso universal $(10 \mu \mathrm{M}), 5 \mu \mathrm{L}$ de cDNA e 778 $\mu \mathrm{L} \mathrm{H}_{2} \mathrm{O}$ MiliQ com os seguintes parâmetros para amplificação: 1) $50{ }^{\circ} \mathrm{C}$ por 2 minutos; 2) 95 ${ }^{\circ} \mathrm{C}$ por 10 minutos; 3) 40 ciclos à $95^{\circ} \mathrm{C}$ por 15 segundos cada ciclo e, 4) $60^{\circ} \mathrm{C}$ por 1 minuto. Após a determinação do número de cópias de cada gene, o valor obtido para os genes de interesse foi normalizado pelos valores dos genes constitutivos contidos na placa (Rat U6 snRNA, RNU43 snoRNA e Hm/Ms/Rt U1 snRNA) que mantiveram valores uniformes em todos os grupos estudados.

\subsection{Análise quantitativa da expressão dos mRNAs/miRNAs por reação em cadeia da polimerase (PCR) em tempo real}

Os mRNAs de interesse e os miRNA significativamente alterados no experimento descrito acima foram confirmados e quantificados por análise quantitativa da expressão gênica por meio da técnica de PCR em tempo real utilizando o aparelho Stratagene Mx3005P ${ }^{\circledR}$ (Agilent Technologies ${ }^{\circledR}$, Santa Clara, CA, Estados Unidos). Os ensaios foram realizados em duplicata utilizando $6,25 \mu \mathrm{L}$ de SYBR Green mix (SABiosciences ${ }^{\mathrm{TM}}$, Frederick, MD, EUA), 4,75 $\mu \mathrm{L}$ de $\mathrm{H}_{2} \mathrm{O}$ MiliQ, 0,5 $\mu \mathrm{L}$ de primer adaptador (UPR) para miRNAs ou primer anti-sense para mRNAs em $10 \mu \mathrm{M}, 0,5 \mu \mathrm{L}$ de cDNA $(6,5 \mathrm{ng}), 0,5 \mu \mathrm{L}$ de primer sense específico para o mRNA/miRNA desejado $(10 \mu \mathrm{M})$ com os seguintes parâmetros de amplificação: (1) etapa inicial de ativação da enzima a $95^{\circ} \mathrm{C}$ por 10 minutos, (2) 40 ciclos que incluíram a desnaturação a $95^{\circ} \mathrm{C}$ por 15 minutos, o anelamento dos primers a $60{ }^{\circ} \mathrm{C}$ (temperatura ótima para todos os pares de primers usados) por 30 segundos e a extensão a $72{ }^{\circ} \mathrm{C}$ por 30 segundos, e (3) um ciclo para análise do melting que consistiu em 95 
${ }^{\circ} \mathrm{C}$ por 30 segundos, $60{ }^{\circ} \mathrm{C}$ por um minuto e posterior aumento gradativo da temperatura para $95^{\circ} \mathrm{C}$ para obtenção das curvas de melting.

O limiar para desconsideração do ruído na fluorescência de cada amostra foi determinado automaticamente pelo software de análise MxPro - Mx 3005P (Agilent Technologies $^{\circledR}$, Santa Clara, CA, Estados Unidos), que também determinou as curvas de melting, além de quantificar o número de cópias de cada gene utilizando o método de derivação secundária. Após a determinação do número de cópias de cada gene, o valor obtido para os genes de interesse foi normalizado pelos valores dos genes constitutivos (U1, 18S e RPL37a), cujos valores mantiveram-se uniformes em todos os grupos estudados.

Quadro 1. Sequência de primers utilizados

\begin{tabular}{|c|c|}
\hline Gene & Sequência \\
\hline Universal & 5' - GGC CAC GCG TCG ACT AGT AC - 3' \\
\hline $29 \mathrm{a}$ & 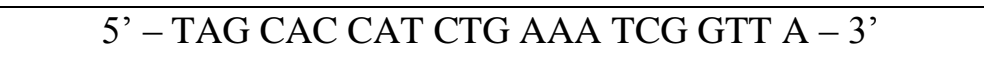 \\
\hline $29 b$ & 5' - TAG CAC CAT TTG AAA TCA GTG TT - 3' \\
\hline $29 \mathrm{c}$ & 5' - TAG CAC CAT TTG AAA TCG GTT A - 3' \\
\hline U1 & 5' - CCA GGG CGA GGC TTA TCC ATT GC - 3' \\
\hline $18 \mathrm{~S}$ & $5^{\prime}$ - GAC TCA ACA CGG GAA ACC TCA CC - 3' \\
\hline RPL37a & 5' - CAA GAA GGT CGG GAT CGT CG - 3' \\
\hline p53 & $\begin{array}{c}\text { Sense: 5' - CGT TGC TCT GAT GGT GAC GG - 3' } \\
\text { Anti-sense: 5'- AGC GTG ATG ATG GTA AGG ATG G - 3' }\end{array}$ \\
\hline PUMA & $\begin{array}{l}\text { Sense: 5' - CGG CGG AGA CAA GAA GAG CAA C - 3' } \\
\text { Anti-sense: 5'- GGC ACC TAG TTG GGC TCC ATT TC - 3' }\end{array}$ \\
\hline PR & $\begin{array}{c}\text { Sense: 5' - CTCCTGGATGAGCCTGATGG - 3' } \\
\text { Anti-sense: 5' -AGGAACTCCTCGTGGGTCAC - 3' }\end{array}$ \\
\hline $\mathrm{NF} \kappa \mathrm{B}$ & $\begin{array}{l}\text { Sense: 5'- CTC AAG AAC AGC AAG GCA GCA C - 3' } \\
\text { Anti-sense: 5'- AGAGGTGTCGTCCCATCGTAGG - 3', }\end{array}$ \\
\hline
\end{tabular}

\subsection{Preparação das amostras para Western Blotting}

Após obtenção de aproximadamente 350 ilhotas pancreáticas o tecido foi ressuspenso em $200 \mu \mathrm{L}$ de tampão para extração do conteúdo celular total, posteriormente homogeneizado em Sonicador Fisher Scientific ${ }^{\circledR}$ (Fisher Scientific ${ }^{\mathrm{TM}}$ Model 505 Sonic Dismembrator, Thermo 
Fisher Scientific, Waltham, MA, Estados Unidos), em 3 vezes de 10 segundos, $4{ }^{\circ} \mathrm{C}$, aquecido por 10 minutos a $97{ }^{\circ} \mathrm{C}$, centrifugado por 20 minutos a $4{ }^{\circ} \mathrm{C}$ em $12000 \mathrm{rpm}$ e $300 \mu \mathrm{L}$ do sobrenadante foi transferido para experimentação.

\subsection{Método Breadford para dosagem de proteínas - protein assay}

A concentração de proteína total foi avaliada por meio do método de Breadford Protein Assay $^{70}$. Foram acrescentados em $2 \mu \mathrm{L}$ de amostra, $18 \mu \mathrm{L}$ de água destilada e, em 294 $\mu \mathrm{L}$ de Breadford diluído conforme especificações do fabricante foi acrescentado $6 \mu \mathrm{L}$ da amostra, em duplicata. Após 10 minutos, protegido contra a exposição da luz, as concentração das amostras foram mensuradas em espectrofotômetro $(670 \mathrm{~nm})$, utilizando uma curva de calibração de albumina bovina sérica (BSA) de 0,05 a 1,0 mg/mL. Os valores de concentração proteica das amostras foram aferidos nesta curva de calibração.

\subsection{Western Blotting - quantificação de proteína}

Conhecidas as concentrações proteicas das diferentes amostras, estas foram submetidas à técnica de "Western Blotting" para a quantificação das proteínas de interesse. O método envolve os seguintes passos:

\subsubsection{Eletroforese em gel de poliacrilamida (SDS-PAGE)}

O primeiro passo consiste em submissão das amostras à eletroforese em gel de poliacrilamida. Desse modo, é possível separar proteínas de acordo com seu peso molecular.

Foi utilizado o método desenvolvido por Laemmli e modificado por Garfin ${ }^{71}$, o qual envolve um sistema descontínuo de dois géis contíguos: o gel de empacotamento, "staking gel”, e o gel de separação, "resolving gel”. Amostras de $30 \mu \mathrm{g}$ de proteína foram solubilizadas em tampão de Laemmli (glicerol 15\%, Tris 0,05 M, Bromophenol Blue 0,05\%, SDS 9\%, 2Mercaptoetanol 6\%) e, então, aquecidas durante 5 minutos. Após aquecimento as amostras foram resfriadas e aplicadas no sistema de corrida.

A eletroforese vertical foi iniciada sob voltagem constante em $60 \mathrm{~V}$ até que ocorresse o empacotamento das amostras, aproximadamente 1 hora. Posteriormente, foi aplicada uma corrente constante de $120 \mathrm{~V}$ para a corrida no gel de separação, aproximadamente $2 \mathrm{~h}$ e $30 \mathrm{~min}$, em tampão de corrida Tris 25 mM, Glicina 190 mM, SDS 0,1\%, EDTA 2 mM, pH 8,3. 
Juntamente com as amostras foi colocado um padrão de proteínas de conhecidos pesos moleculares.

\subsubsection{Transferência por eletroforese}

Após a separação das frações proteicas, foi realizada a transferência eletroforética dessas frações para uma membrana de nitrocelulose Hybond-C Super (GE healthcare, AMERSHAM Biosciences, UK), sob corrente constate de $15 \mathrm{~V}$, por 45 minutos para uma membrana acrescido de 15 minutos a cada membrana colocada no equipamento Semi-Dry Transfer Cell, Bio-Rad ${ }^{\circledR}$ (Bio-Rad Laboratories,Hercules, CA, Estados Unidos). A qualidade da transferência foi verificada corando-se o gel com azul brilhante de Comassie ${ }^{72}$.

\subsubsection{Imunodetecção}

Após a transferência por eletroforese, iniciou-se o processo de imunodetecção ${ }^{73}$. Primeiramente, realizou-se um bloqueio inespecífico com leite desnatado à $5 \%$, overnight a 4 ${ }^{\circ} \mathrm{C}$ em agitação constante e, em seguida, a membrana foi incubada com anticorpo de acordo com a proteína de interesse em 3\% de BSA com diluição de acordo com especificações do fabricante, overnight a $4{ }^{\circ} \mathrm{C}$ em agitação constante.

Posteriormente foi realizada uma incubação com o anticorpo secundário específico para cada anticorpo utilizado, durante 1 hora em temperatura ambiente sob agitação constante. Em seguida, a membrana foi lavada vigorosamente com solução de lavagem e colocada em contato com solução de detecção $\left(\mathrm{H}_{2} \mathrm{O}\right.$ destilada + Luminol + Ác. P-Cumárico + Tris $1 \mathrm{M}$ [pH 8,5] + Peróxido de Hidrogênio) por 1 minuto. Por fim, a membrana foi exposta ao equipamento Bio-Imaging Systems, MF-ChemiBis 3.2 (BioAmerica Inc., Florianópolis, SC, Brasil), por períodos de 1,5 a 3 minutos para detecção das bandas resultantes. Após este período o resultado foi obtido e capturado por meio do software do próprio equipamento, GelCapture Acquisition Software (DNR Bio-Imaging System).

Os anticorpos primários utilizados foram: anti-p53 (BD Pharmigen, Cat. \#554157, CA, USA), anti-sintaxina-1 (Abcam, Cat \#ab78539, Cambridge, UK), anti-JNK (millipore, Cat \#06-748, Darmstadt, Alemanha), anti-pJNK (millipore, Cat \#07-175, Darmstadt, Alemanha), anti-IKK (Santa Cruz, Cat \#10760, California, USA), anti-pIKK (Santa Cruz, Cat \#21661, California, USA), anti-IKB (Santa Cruz, Cat \#1643, California, USA), anti-pIKB (Santa Cruz, Cat \#7977, California, USA), anti-PR (Santa Cruz, Cat \#539, California, USA), anti-NFkB 
(eBioscience, Cat \#14-6731-81, San Diego, CA, USA) e anti-alfa tubulina (Invitrogen, Cat \#32-2500, CA, USA). O anticorpo secundário conjugado com peroxidase (Bio-Rad, Bio-Rad Laboratories, Hercules, CA, EUA) foi utilizado segundo orientação do fabricante.

\subsubsection{Expressão dos resultados}

As imagens capturadas foram analisadas por densidometria utilizando-se o software ImageJ 1.47. A intensidade das imagens de cada amostra foi normalizada pela equivalente de alfa-tubulina, e os valores foram expressos como unidades arbitrárias.

\subsection{Imunohistoquímica}

O pâncreas dos animais de todos os grupos experimentais foi cuidadosamente retirado, eliminando linfonodos e gordura, e separados em parte duodenal ("cabeça") e parte do baço (“cauda"). Após a pesagem, cabeça e cauda foram fixadas em solução de Bouin por 12 horas, desidratados em etanol e incluídos em parafina. Secções sequenciais $(15 \mu \mathrm{m})$ das partes da cauda foram obtidas com a utilização de um micrótomo rotativo e colocadas em lâminas sinalizadas individuais.

Em seguida as secções foram desparafinizadas em xileno e reidratadas. A atividade da peroxidase endógena foi eliminada por meio da incubação das lâminas com $\mathrm{H}_{2} \mathrm{O}_{2}$ a $3 \%$ durante 10 minutos. As secções foram lavadas com tampão fosfato $0,1 \mathrm{M}(\mathrm{pH} 7,4)$, bloqueadas com $5 \%$ de leite seco desnatado (diluído em tampão de fosfato contendo $0,05 \%$ de Tween-20) e incubados com anticorpo de cobaia anti-insulina (1:150) (Dako, Agilent Technologies, cat. \#A0564, Santa Clara, CA, Estados Unidos) a $4{ }^{\circ} \mathrm{C}$ overnight. Posteriormente os cortes foram lavados e incubados com anti-IgC biotinilado de cobaia em temperatura ambiente durante 1 hora.

Os complexos de estreptavidina-biotina foram detectados com solução de diaminobenzidina (DAB) $\left(0,1 \%\right.$ de DAB e $0,02 \%$ de $\mathrm{H}_{2} \mathrm{O}_{2}$ em PBS). Finalmente as secções foram coradas com hematoxilina de Harris e montadas para observação em microscopia LEICA DM 5000B (Leica Microsystems, Solms, Alemanha). As imagens foram obtidas usando uma câmera CCD LEICA CTR 5000 (Leica Microsystems, Solms, Alemanha) e o software LEICA Q Win Plus v. 3.2.0. Aleatoriamente 12 a 15 campos a partir de partes da cauda de cada animal foram analisados. 


\subsection{Imunofluorescência}

O pâncreas de ratas em G20 foi perfundido com solução de paraformaldeído $1 \%$ dissolvido em $100 \mathrm{mM}$ de tampão fosfato (PBS), pH 7,3. Em seguida o tecido foi extraído e seguimentado, de modo que somente a cauda do pâncreas foi utilizado, sendo pós fixado na mesma solução de perfusão, por uma hora. Após uma hora o tecido foi colocado em solução de sacarose $30 \%, 4{ }^{\circ} \mathrm{C}$, por 3 dias, para crioproteção. Após crioproteção, os tecidos foram emblocados em meio de inclusão OCT (Optimal Cutting Temperature - OCT, 4583, Sakura Finetek, Inc., Torrance, CA, USA) congelados em gelo seco e mantidos em $-80{ }^{\circ} \mathrm{C}$.

O tecido foi seccionado em $20 \mu \mathrm{m}$ utilizando criostato Leica CM 3050 (Leica Microsystems, Wetzlar, Alemanha).A preparação das lâminas foi realizada a partir de cortes seriados na porção caudal do pâncreas.

Para o ensaio de imunofluorescência, as secções do pâncreas foram bloqueadas por 2 horas em solução de PBS contendo 5\% de albumina bovina sérica (BSA). Em seguida, os cortes foram incubados com dupla marcação para determinar a imunorreatividade de granulócito HIS48 (FITC, BD Pharmingen ${ }^{\text {TM }}$ - BD Biosciences, Franklin Lakes, NJ, Estados Unidos) e insulina (Dako, Agilent Technologies, cat. \#A0564, Santa Clara, CA, Estados Unidos) afim de especificar somente as ilhotas pancreáticas, ambos em uma diluição de 1:50 em solução de $\mathrm{PBS}$ com $3 \%$ de $\mathrm{BSA}, 4{ }^{\circ} \mathrm{C}$, em câmara úmida, overnight. Após lavagens seriadas as secções foram incubadas com anticorpo secundário conjugado ao fluoróforo (FITC e TRITC respectivamente, 1:50) em solução de PBS com 1\% de BSA.

As lâminas foram analisadas utilizando microscópio óptico fluorescente (Nikon Eclipse E1000, Fukuoka, Japão) com uma câmera acoplada a este (Nikon DS-Fi1, Japão). Após captura, as imagens foram sobrepostas para investigar possível infiltrado inflamatório, por meio do programa Nis-Elements (Nikon Corporation, Japão). Os controles experimentais consistiram na omissão do anticorpo primário, sem marcações observadas.

\subsection{Análise dos dados}

Os resultados foram apresentados como média \pm EPM. Para comparação das médias entre os grupos das curvas glicêmicas geradas a partir do GTT foi calculada a área sob a curva a partir do ponto 0 e, para a curva glicêmica gerada a partir do ITT foi calculado logaritmo neperiano $[\mathrm{Y}=\mathrm{Ln}(\mathrm{Y})]$ dos dados e, posteriormente realizada a regressão linear dos valores obtidos. Para ambos os testes, bem como para os valores de expressão gênica e conteúdo 
proteico, para os dados morfométricos e para o perfil hormonal os resultados foram avaliados por meio do teste ANOVA de uma via, paramétrico, com pós-hoc Tukey utilizando o software GraphPad Prism, versão 5. As diferenças entre os grupos foram consideradas significantes quando o valor de $P$ fosse menor que 0,05 . 


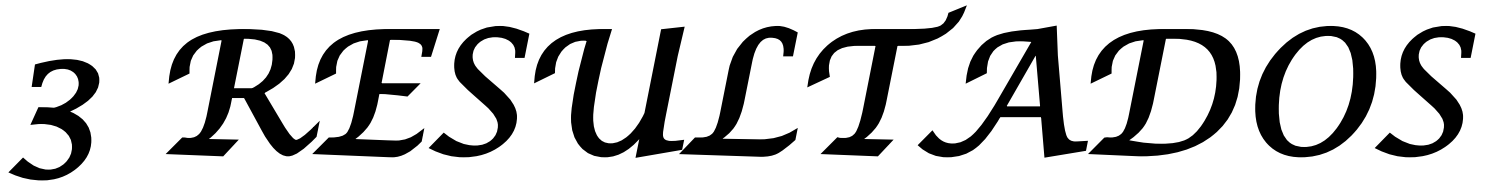




\subsection{Morfometria}

Seis dias de tratamento com DEXA promoveu a perda de peso em ratas virgens e evitou o ganho de peso em ratas grávidas entre os $14^{\circ}$ e $19^{\circ}$ dias de gestação. Além disso, ratas grávidas não tratadas não apresentaram alterações no peso corporal ao longo dos 21 dias de lactação. Por outro lado, ratas que receberam DEXA durante a gravidez apresentaram acentuado ganho de peso entre o $1^{\circ}$ e o $14^{\circ}$ dia de lactação, sendo que no $14^{\circ}$ dia pós parto o peso corporal das mesmas foi semelhante às mães não tratadas (Figura 3a).

Um aumento significativo, mas transiente, nos níveis de glicose foi observada em ratas virgens tratadas com DEXA entre os $2^{\circ}$ e $5^{\circ}$ dias de tratamento, enquanto que em ratas grávidas, independentemente do tratamento, os níveis de glicose circulante foram reduzidos (Figura 3b). Após o fim do tratamento, ratas virgens que receberam DEXA apresentaram intolerância à glicose enquanto que ratas grávidas, tratadas ou não com DEXA, não foram intolerantes à glicose (Figura $3 \mathrm{c}$ e d). Por fim, o peso corporal de ratas grávidas tratadas com DEXA, 3 meses após o desmame da prole, foi significativamente maior em relação às ratas grávidas não tratadas. (Figura 3e). 
a)

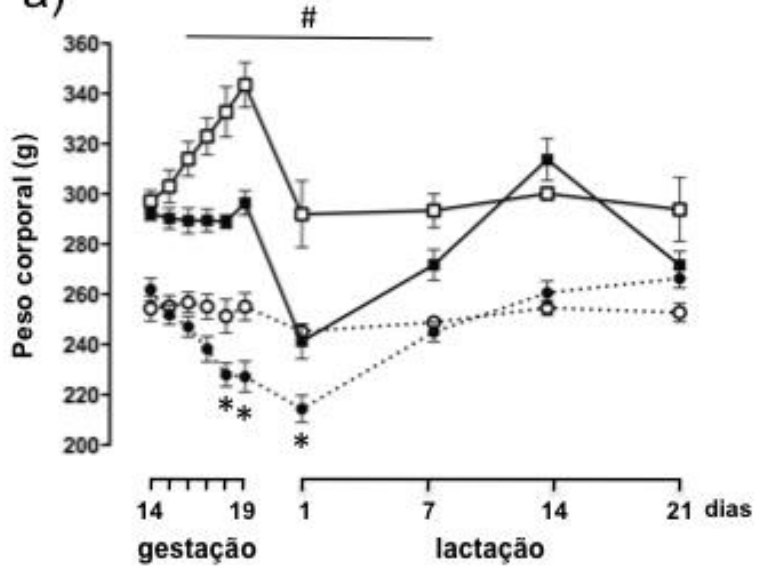

c)

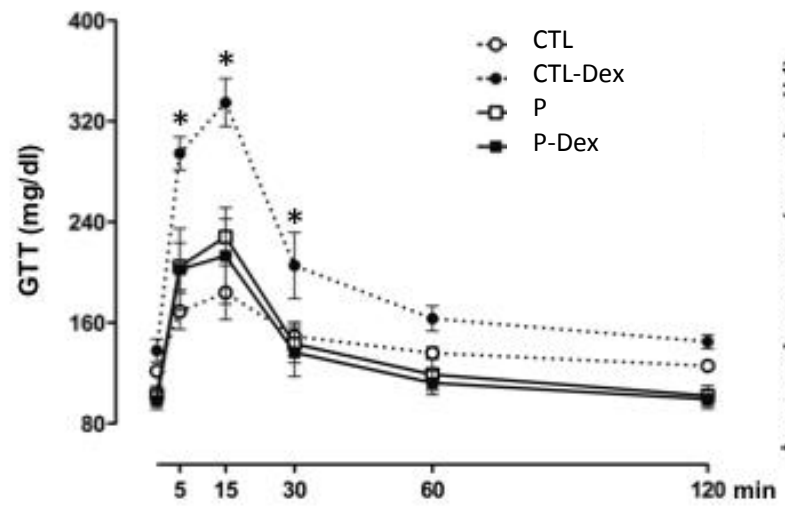

b)

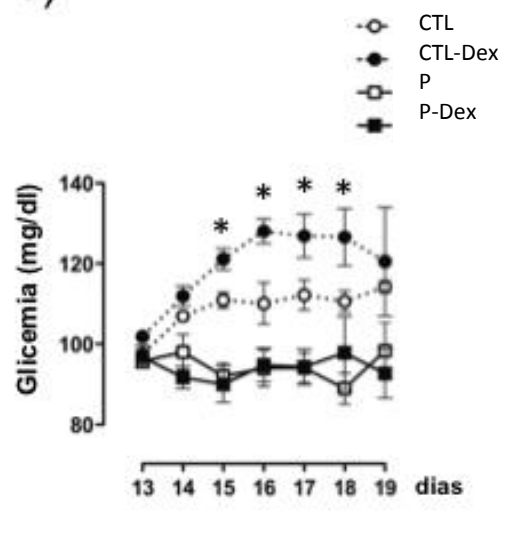

d)

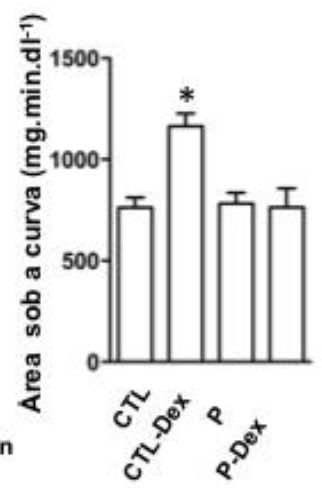

e)

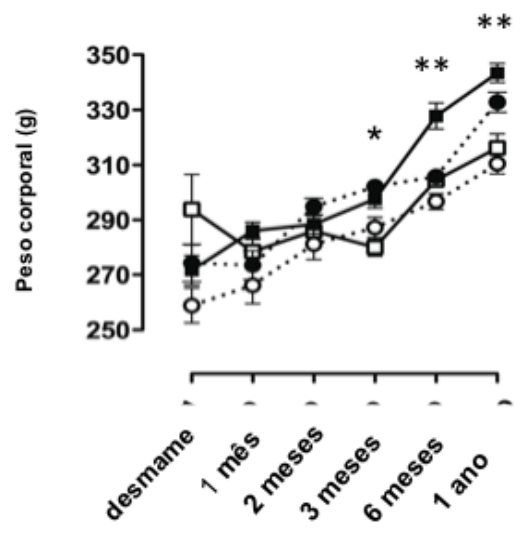

Figura 3. Evolução do peso corporal do $14^{\circ}$ dia de gestação até o final da lactação (a), glicemia matutina antes e durante o tratamento com DEXA (b), tolerância à glicose no dia seguinte do final do tratamento (c, d) e peso corporal do desmame até 1 ano após (e) de ratas CTL (círculos abertos), CTL-Dex (círculos cheios), P (quadrados abertos) e P-Dex (quadrados cheios). * p >0.05 CTL-Dex vs. CTL, P e P-Dex, ** p >0.05 P-Dex vs. P e \# p>0.05 P-Dex vs. CTL, CTL-Dex e P. $n=6-10$. 


\subsection{Teste de tolerância à glicose}

A curva glicêmica demonstrou que a sensibilidade à glicose é regulada em diferentes momentos. Após a lactação ratas grávidas tratadas com DEXA apresentaram intolerância à glicose (Figura 4a), quadro este revertido posteriormente (Figura 4b, 4c). Contudo, no terceiro mês após o desmame (Figura 4d) o mesmo grupo volta a tornar-se intolerante em relação aos demais e essa condição persiste até um ano após o desmame (Figura 4e, 4f).

a)
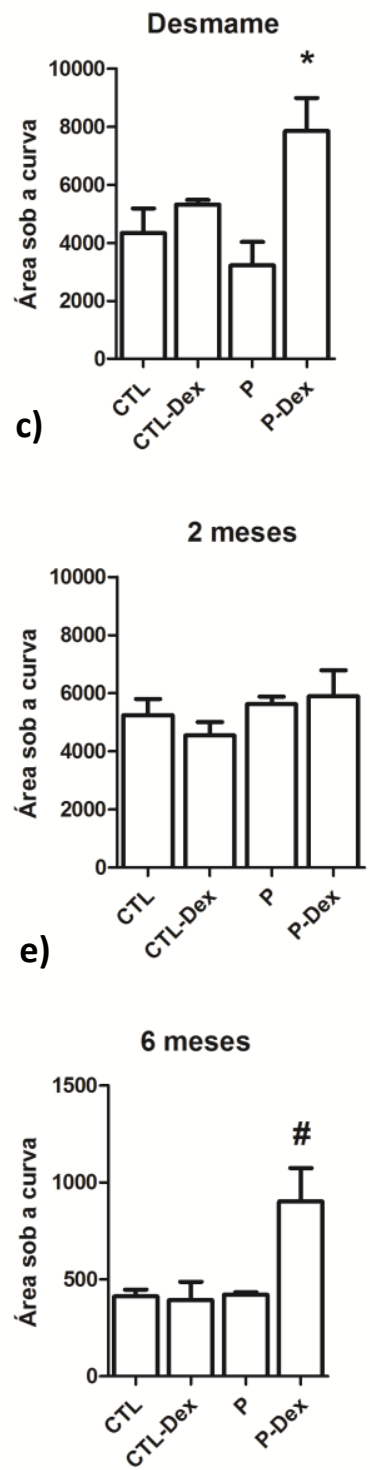

b)
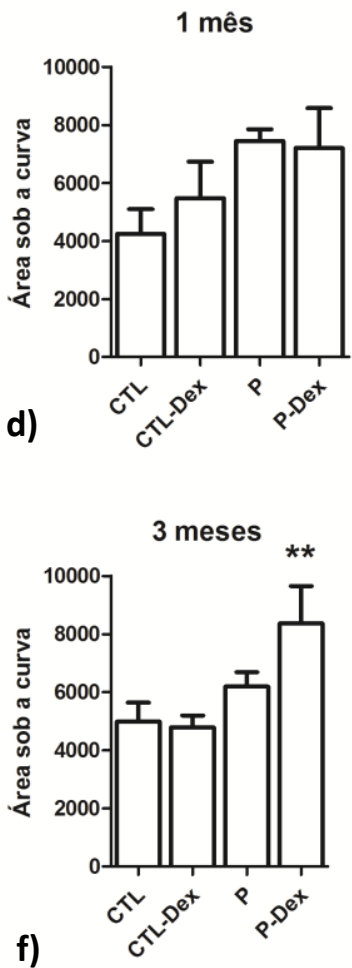

1 ano

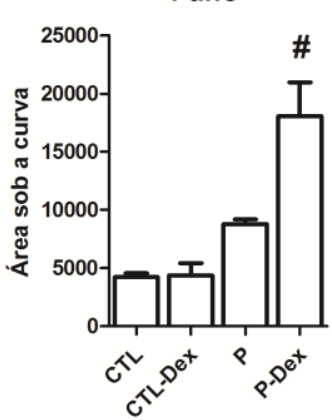

Figura 4. Teste de tolerância à glicose (GTT) de ratas CTL, CTL-Dex, $P$ e P-Dex. O GTT foi realizado entre o desmame da prole (a) até um ano após o desmame (f). * p>0.05 P-Dex vs. CTL e P, ** p>0.05 P-Dex vs. CTL e CTL-Dex, \# p>0.05 P-Dex vs. CTL, CTL-Dex e P. n=5-9. 


\subsection{Teste de tolerância à insulina}

Após o teste de tolerância à insulina foi possível observar que não houve diferença na sensibilidade entre os grupos (Figura 5).

a)

Desmame

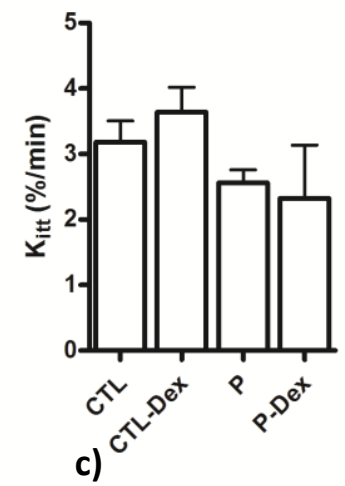

2 meses

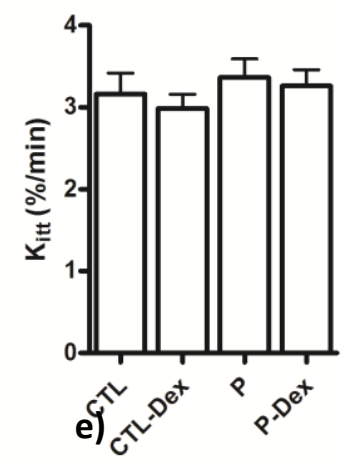

6 meses

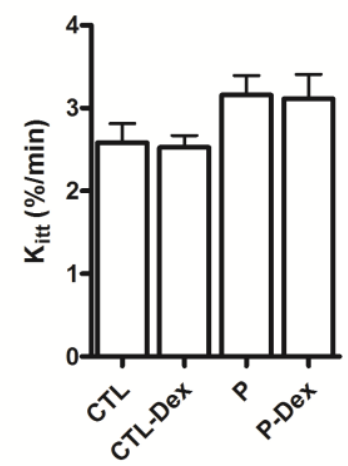

b)

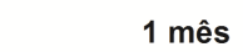

d)

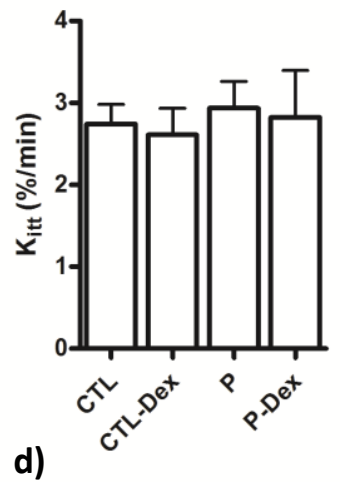

3 meses

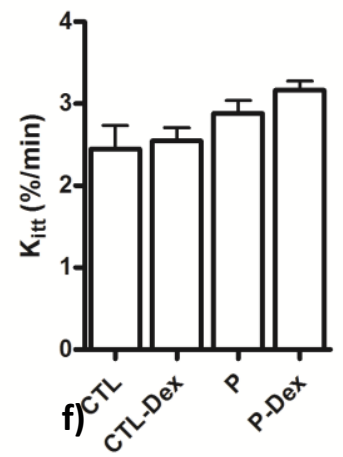

1 ano

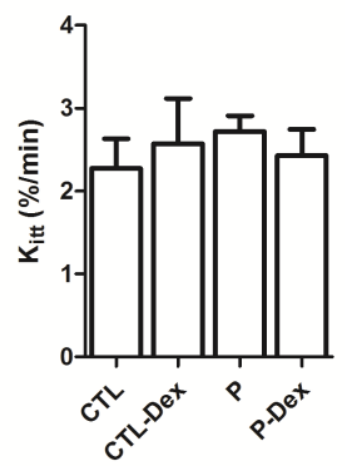

Figura 5. Teste de tolerância à insulina (ITT) de ratas CTL, CTL-Dex, P e P-Dex. O ITT foi realizado entre o desmame da prole (a) até um ano após o desmame (f). n=5-9. 


\subsection{Secreção estática de insulina}

Não foi evidenciada alterações na secreção estática de insulina logo após a gestação tratada ou não com DEXA, porém, um ano após o desmame da prole foi possível constatar redução do limiar e responsividade à glicose em ratas grávidas tratadas durante o $14^{\circ}$ e $19^{\circ}$ dias de gestação.

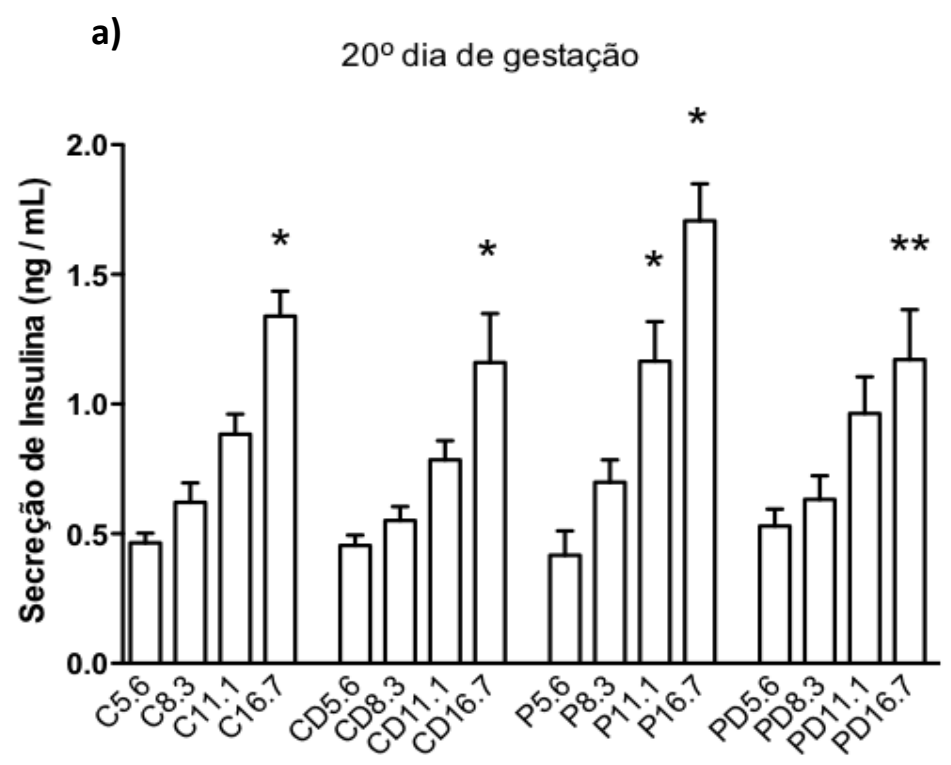

b)

1 ano após o desmame

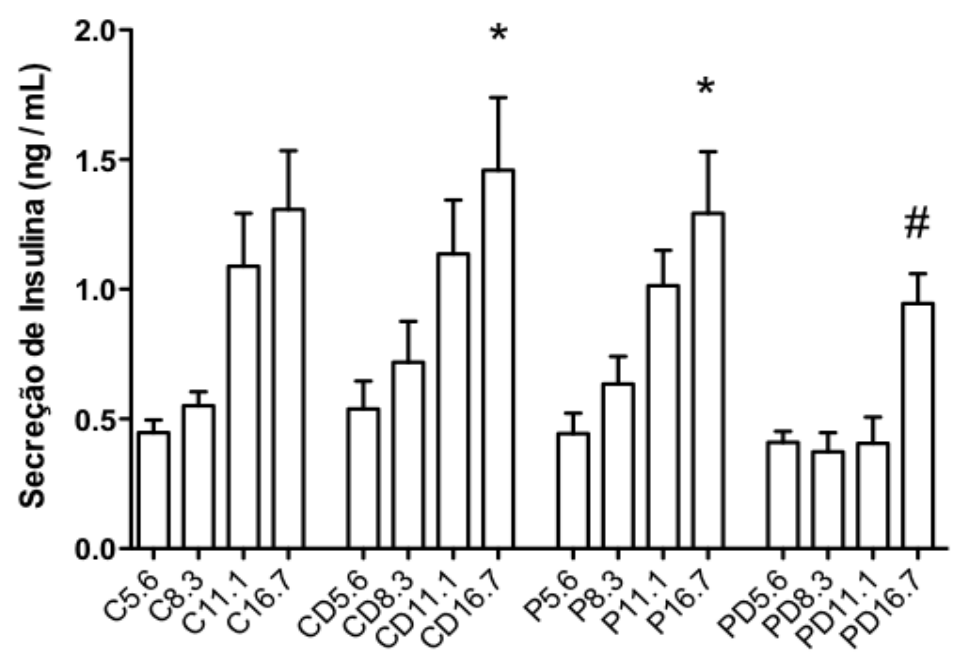

Figura 6. Secreção estática de insulina estimulada por glicose no $20^{\circ}$ dia de gestação e um ano após o desmame, respectivamente. * $p<0,0516.7 \mathrm{ng} / \mathrm{mL}$ vs $5.6 \mathrm{ng} / \mathrm{mL}$; ** $p<0,0516.7 \mathrm{ng} / \mathrm{mL}$ vs 5.6 e $8.3 \mathrm{ng} / \mathrm{mL}$; \#p<0,05 16.7 $\mathrm{ng} / \mathrm{mL}$ vs $5.6,8.3$ e $11.1 \mathrm{ng} / \mathrm{mL} \mathrm{n}=5-6$ animais. 


\subsection{Imunohistoquímica}

A arquitetura das ilhotas pancreáticas e de células beta insulina-positivas foram conservadas em todos os grupos (Figura 7). Foram detectadas células beta no núcleo das ilhotas (distribuição típica de ilhotas de ratos), e o tamanho e o número das mesmas não foram alterados no $20^{\circ}$ dia de gestação. A histomorfometria mostrou que o perímetro médio das ilhotas foi menor que $500 \mu \mathrm{m}$ nos quatro grupos (variando de $414 \pm 24 \mu \mathrm{m}$ em grávidas tratadas com DEXA para $488 \pm 48 \mu \mathrm{m}$ em virgem tratadas com DEXA). A massa do pâncreas em relação ao peso corporal também foi semelhante entre todos os grupos (variando de $0,36 \pm$ $0,015 \%$ em grávidas para $0,48 \pm 0,06 \%$ em grávidas tratadas com DEXA).

\section{Controle Controle Dexa}
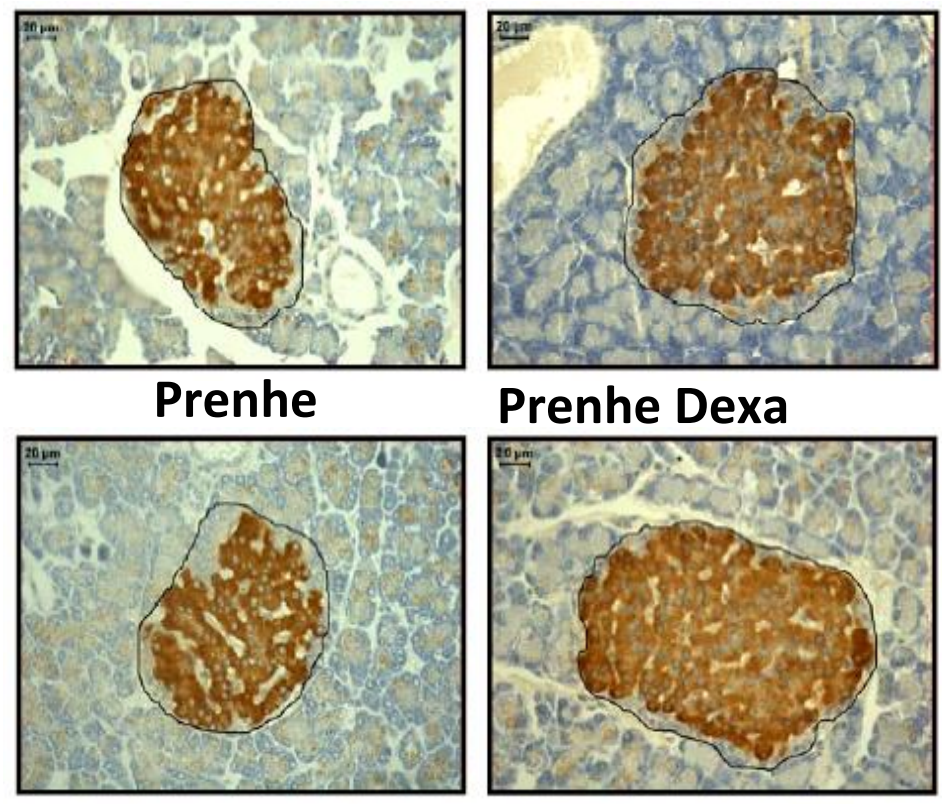

\section{Prenhe Dexa}

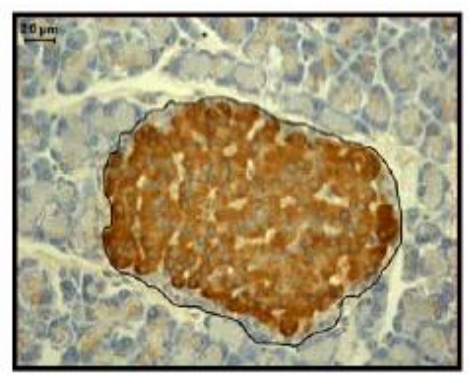

\section{Controle Negativo}

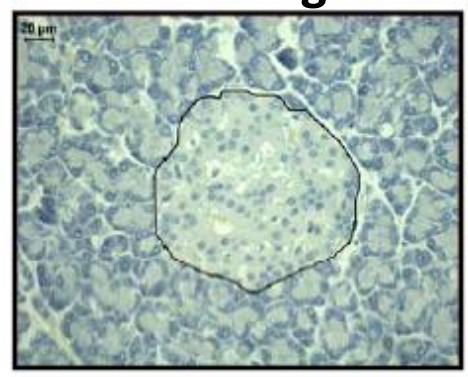

Figura 7. Detecção imunohistoquímica de insulina no pâncreas de ratas CTL, CTL-Dex, P e P-Dex em G20. As imagens digitais foram obtidas utilizando uma câmara CCD (LEICA CTR 5000) e o software LEICA Q Win Plus, v 3.2.0; $(\mathrm{n}=3)$. 


\subsection{Perfil hormonal}

De acordo com a análise sérica foi observado que os grupos tratados com DEXA, prenhes ou não, apresentam conteúdo plasmático de corticosterona diminuído em relação aos grupos que não ingeriram DEXA (Fig. 8a). Além disso, ratas prenhes possuem elevação nos níveis de progesterona circulantes em relação aos demais, enquanto que não houve diferenças expressivas nas concentrações de estrógeno (Fig. 8b e 8c).

a)

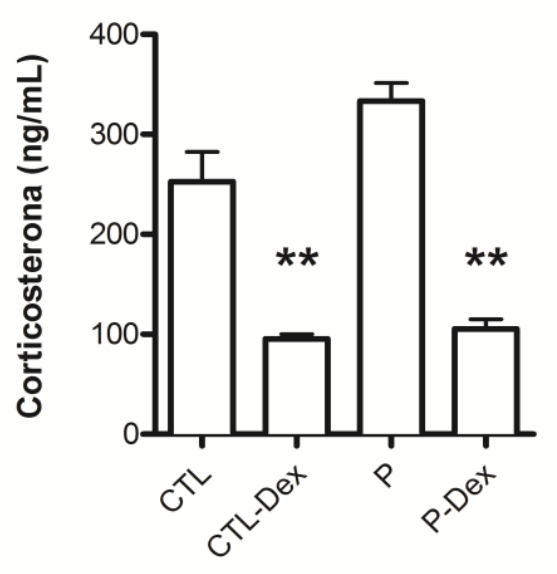

b)

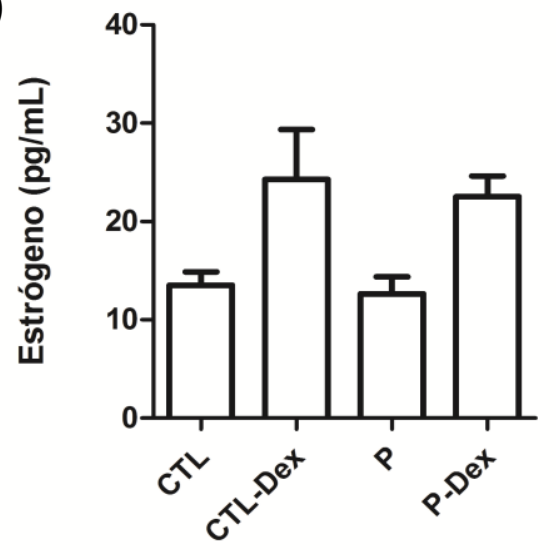

c)

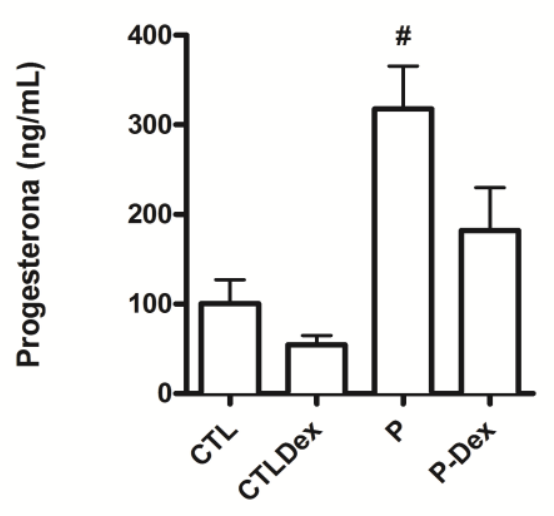

Figura 8. Dosagem sérica hormonal de a) corticosterona, b) estrógeno e c) progesterona, após o tratamento com DEXA (G20). $* * p<0,05$ vs. CTL e P; \#p<0,05 vs. CTL e CTL-Dex. $\mathrm{n}=5-10$ animais. 


\subsection{Análise da expressão dos miRNAs por PCR em tempo real}

A expressão de miR-29a foi reduzida em ilhotas de ratas virgens um dia após o fim do tratamento de DEXA. Esta modulação, no entanto, não foi observada posteriormente. No grupo tratado durante a gestação, observou-se um aumento do miR-29a um dia após o fim do tratamento. Neste caso, esta modulação caracterizou-se como uma resposta sustentada já que a expressão do miR-29a permaneceu elevada 12 meses após o desmame (Figuras 9a e 9b, respectivamente).

A expressão de miR-29b não foi modulada pelo tratamento com DEXA em ilhotas de ratas virgens. No entanto, o tratamento em ratas grávidas resultou em aumento dos níveis de miR-29b um dia após o fim do tratamento, bem como 12 meses após o desmame (Figuras 9c e $9 \mathrm{~d}$, respectivamente). A expressão de miR-29c foi reduzida em ilhotas de ratas virgens um dia após o fim do tratamento de DEXA, porém, em ratas grávidas tratadas a expressão de miR29c foi aumentada um dia após o fim do tratamento (Figura 9e). Por fim, o efeito em longo prazo sobre a expressão de miR-29c foi caracterizada por sua regulação positiva devido à exposição prévia a DEXA, aumentada em ilhotas de ratas virgens cerca de 13 meses após o fim do tratamento. No caso das ratas que foram tratados com DEXA durante a gravidez, a regulação positiva do miR-29c ainda era detectável 12 meses após o desmame (Figura 9f). 
a)

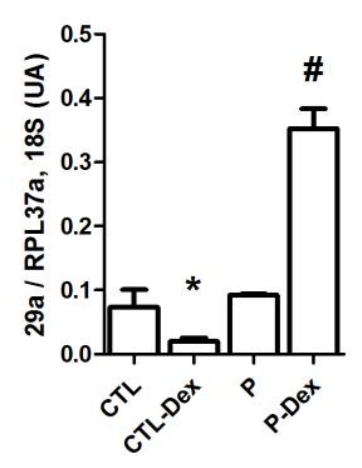

c)

e)
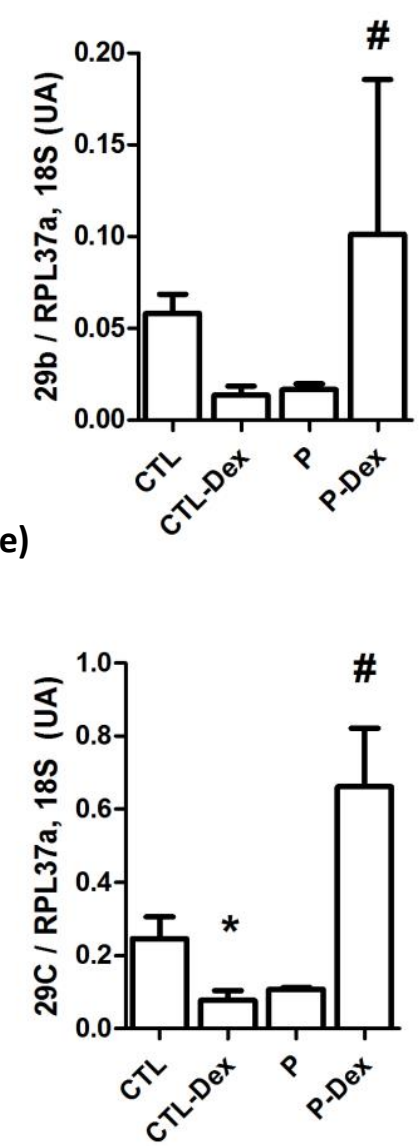

b)

1 ano após o desmame

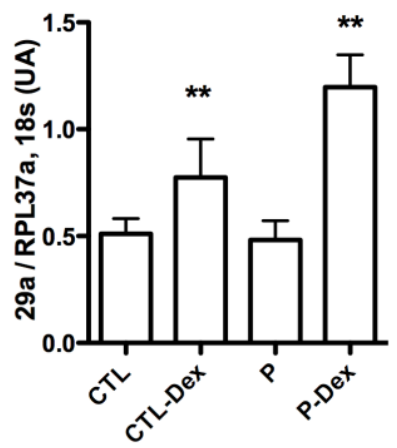

d)

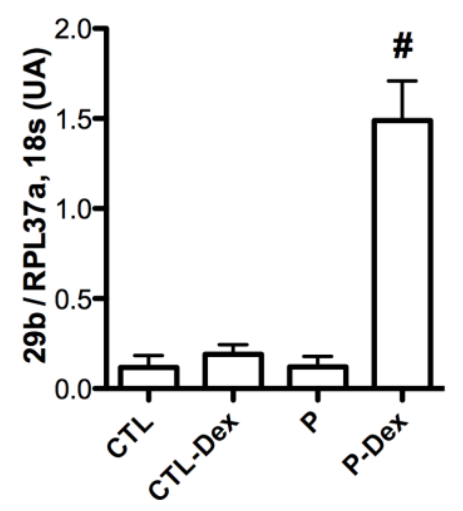

f)

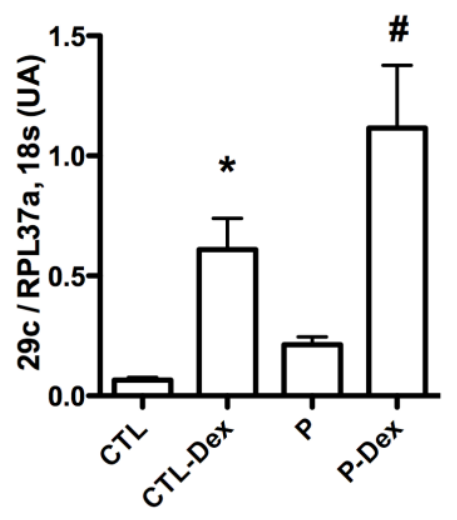

Figura 9. Expressão dos miRNA miR-29a (a, b), miR-29b (c, d) e miR-29c (e, f) em ilhotas de ratas CTL, CTLDex, P e P-Dex. Os RNAs foram obtidos no $20^{\circ}$ dia de gestação (a, c, e) e 1 ano após o desmame (b, d, f). * p $>0.05$ CTL-Dex vs. CTL e P-Dex, ** p>0.05 vs. CTL e P, e \# p>0.05 P-Dex vs. CTL, CTL-Dex e P. n=5-1.

\subsection{Análise da expressão dos mRNAs alvos por PCR em tempo real e quantificação proteica por imunoblotting de p53, PUMA e Stx-1}

A expressão de p53 foi aumentada tanto no conteúdo de mRNA como de proteína nas ilhotas pancreáticas de P-Dex, um dia após o fim do tratamento (Figuras 10a e 10.1.a, respectivamente). Tal alteração permaneceu 12 meses após o desmame, além disso, tanto a 
expressão gênica como o conteúdo proteico foi aumentado em longo prazo após o tratamento DEXA, independentemente da prenhez (Figura 10.1.b).

A seguir, foi avaliada a expressão de PUMA, um alvo direto da atividade transcricional de $\mathrm{p} 53^{74}$.A expressão do mRNA que codifica PUMA foi aumentada em P-Dex. Esta supra-regulação foi detectada em G20 e 1 ano após o desmame (Figuras 10c e 10d, respectivamente). Por sua vez, Sintaxina 1a (STX-1a), uma proteína t-SNARE que desempenha papel crucial na secreção de insulina estimulada por glicose $\mathrm{e}^{75,76}$ e regulada diretamente pelo miR-29 $9^{77}$, após o tratamento com DEXA resultou em níveis reduzidos 1 ano após o desmame (Figura 10.1.d).

a)

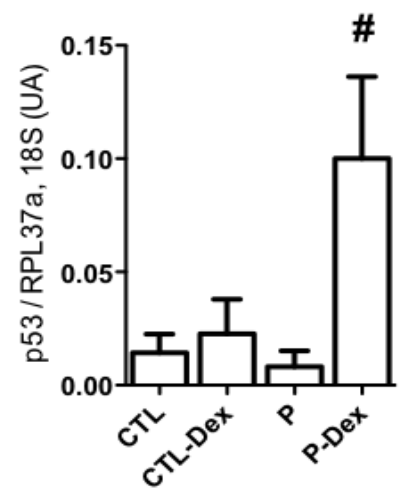

c)

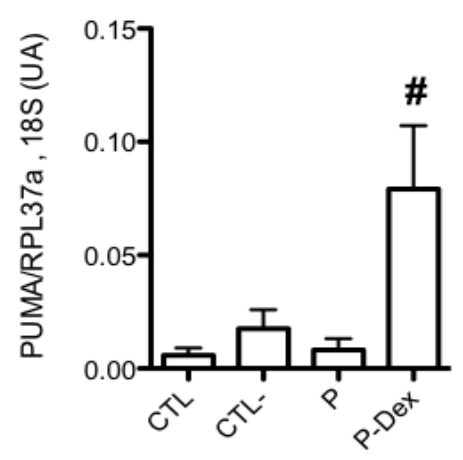

c)

1 ano após o desmame

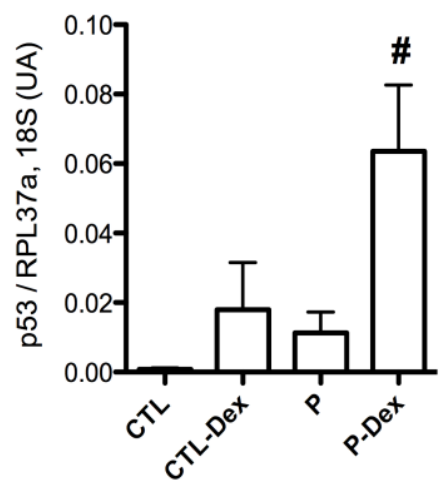

d)

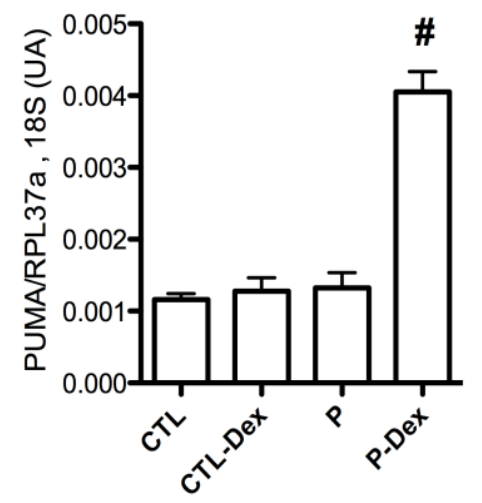

Figura 10. Expressão dos mRNA p53 (a, b) e PUMA (c ,d) em ilhotas de ratas CTL, CTL-Dex, P e P-Dex. Os RNAs foram obtidos no $20^{\circ}$ dia de gestação (a, c) e 12 meses após o desmame (b, d). \#p < 0,0012 P-Dex vs. CTL, CTL-Dex e P. $n=5-9$ animais. 

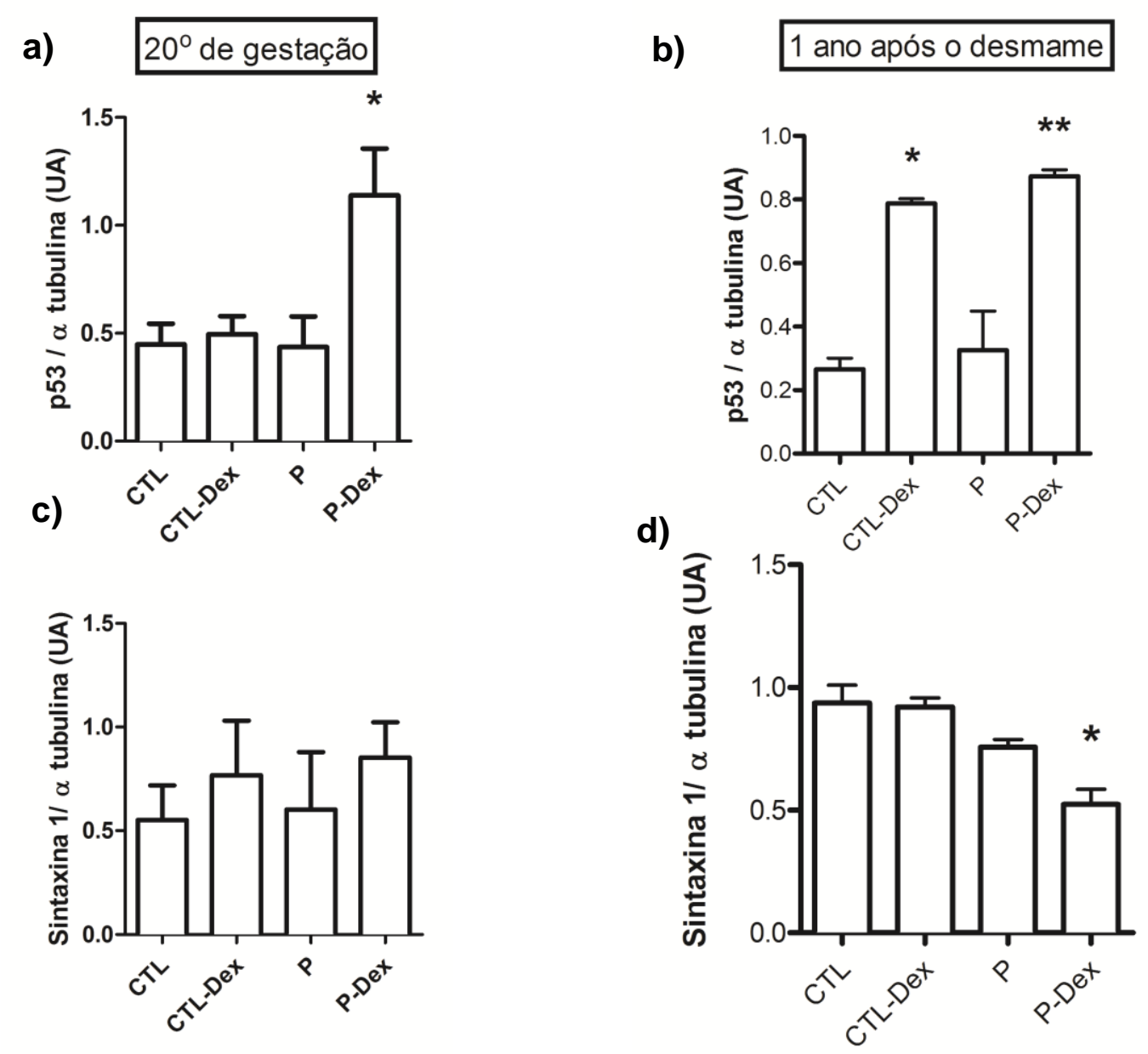

Figura 10.1. Conteúdo proteico de p53 (a, b) e Sintaxinala (c, d) em ilhotas de ratas CTL, CTL-Dex, P e P-Dex. Os RNAs foram obtidos no $20^{\circ}$ dia de gestação (a, c, e) e 1 ano após o desmame (b, d, f). ${ }^{\#} p<0,001$ P-Dex vs. CTL, CTL-Dex e P; $* p<0,007$ P-Dex vs. CTL-Dex; $* * p<0,001$ vs. CTL e P. $\mathrm{n}=5-9$ animais.

\subsection{Análise de mecanismos desencadeadores da perda tardia da função pancreática de ratas tratadas com DEXA durante $o 3^{\circ}$ período gestacional}

Já está bem estabelecido que o ganho de função do pâncreas endócrino materno observado no terceiro período gestacional é um fenômeno que, em condições normais, é coordenadamente revertido nos primeiros dias de lactação ${ }^{12,14}$. Com o intuito de investigar os possíveis mecanismos que poderiam alterar o remodelamento pós-natal da ilhota e, por conseguinte a função pancreática em longo prazo iniciou a análise de vias candidatas.

O final da gestação é considerado como um estado de meta-inflamação ${ }^{78}$. Assim, na primeira etapa desta parte do estudo exploramos alguns marcadores de inflamação nas ilhotas de ratas prenhes submetidas ou não ao tratamento com DEXA. 


\subsubsection{Imunofluorescência}

Após dupla marcação das ilhotas pancreáticas para detecção de insulina e granulócitos, foi detectada a presença de infiltrado inflamatório no grupo de ratas prenhes $(\mathrm{P})$ ao final do tratamento com DEXA (G20).

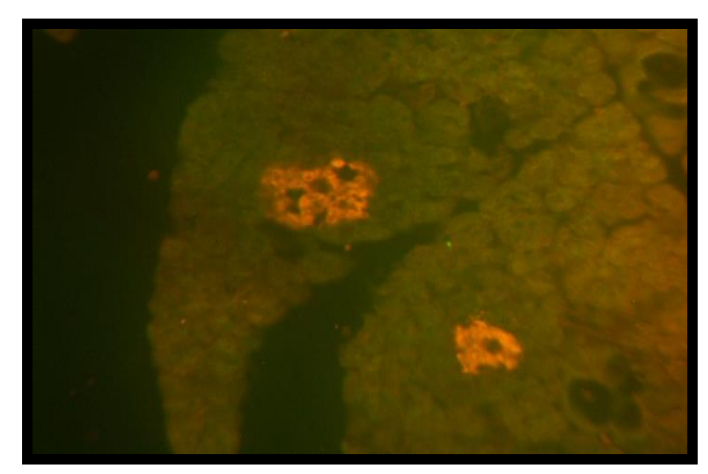

Controle

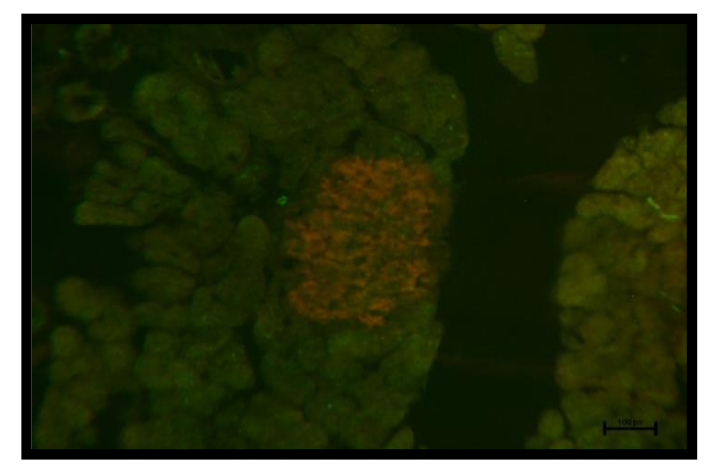

Prenhe

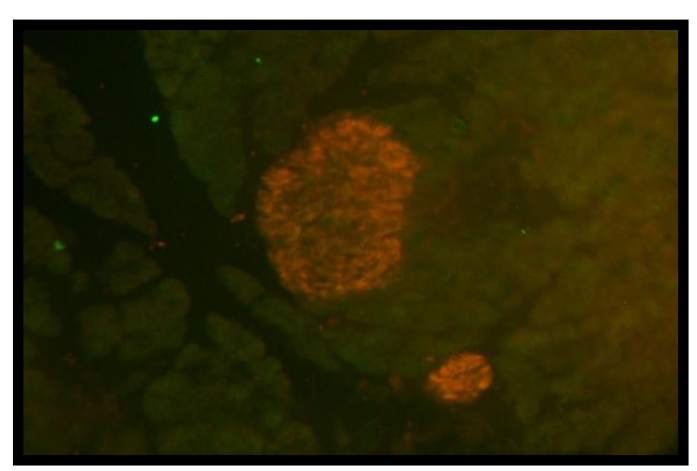

Controle DEXA

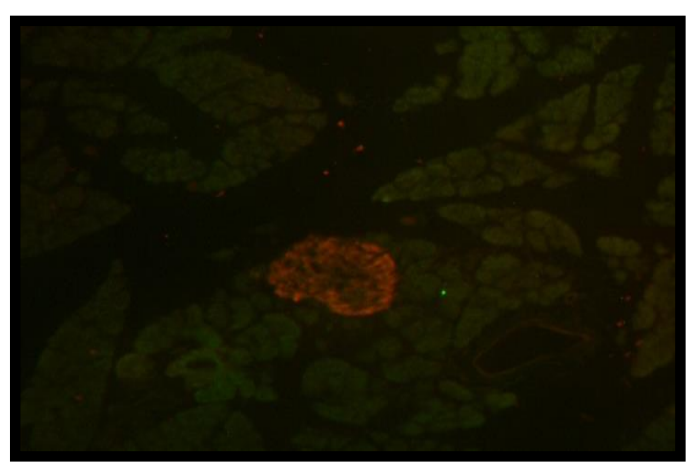

Prenhe DEXA

Figura 11. Detecção por imuno-fluorescência de insulina e granulócito em pâncreas de ratas Controle, Controle DEXA, Prenhe e Prenhe DEXA em G20. As imagens digitais foram obtidas utilizando uma câmara Nikon DSFi1 e o software Nis-Elements, $(n=3)$.

\subsubsection{Expressão e fosforilação da via JNK/NF KB em G20}

A fosforilação de JNK relativa ao seu conteúdo foi reduzida nas ilhotas pela exposição à DEXA no final da gestação (Figura 12a). Paralelamente, as ilhotas de ratas P-Dex apresentaram aumento da fosforilação de IKB e redução de seu conteúdo (Figuras 12c e 12d), e redução da expressão de NFkB (Figura 12e), com tendência à redução de seu conteúdo 
proteico (Figura 12f). Entretanto, nenhuma alteração foi observada na fosforilação de IKK relativa ao seu conteúdo (Figura 12b).

a)

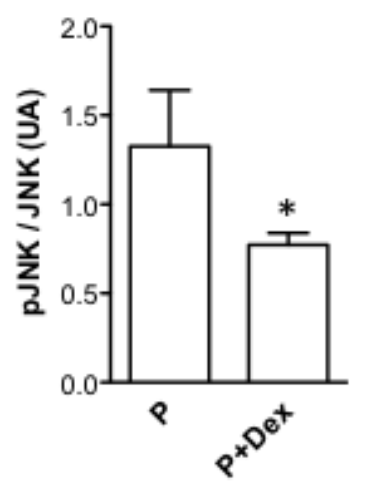

c)

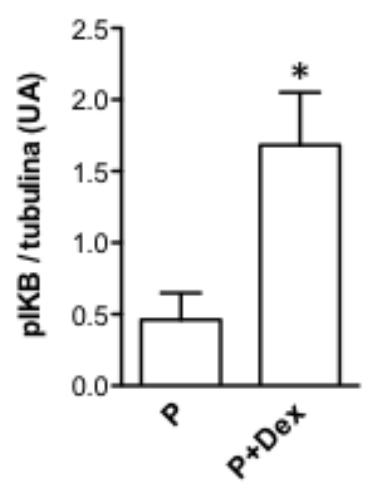

e)

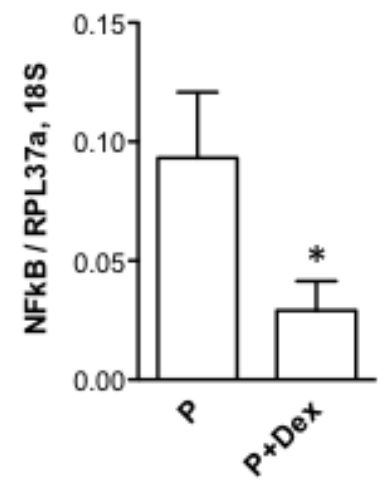

b)

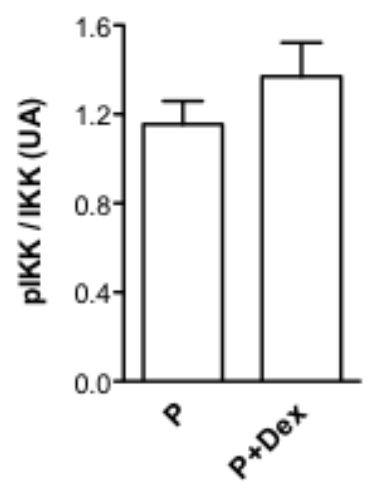

d)

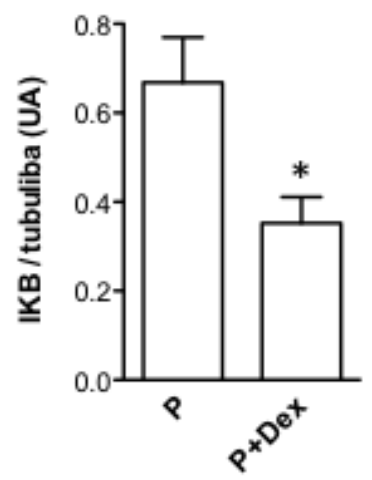

f)

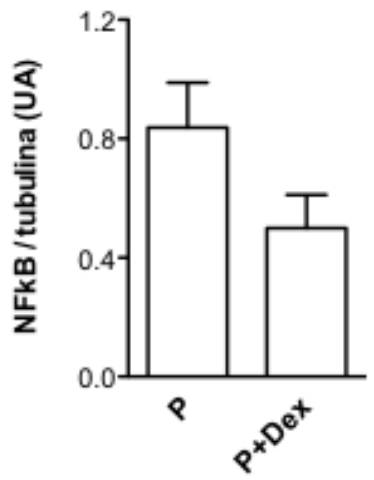

Figura 12. Conteúdo proteico de pJNK (a), pIKK (b), pIKB (c), IKB (d) e NFkB (f) e expressão gênica de NFkB (e) em ilhotas de ratas P e P-Dex, obtidos no $20^{\circ}$ dia de gestação. ${ }^{*} p<0,05$ vs. P. $\mathrm{n}=5-10$ animais. 


\subsection{Análise da expressão dos mRNAs por PCR em tempo real e quantificação proteica por imunoblotting de PR}

Tanto a expressão gênica do receptor de progesterona (PR) como o conteúdo proteico estão aumentadas no grupo de ratas prenhes. Em contrapartida, a expressão gênica deste receptor no grupo de ratas prenhes tratadas com DEXA está significativamente diminuída e seu conteúdo proteico apresenta 49,53\% de diminuição em relação ao grupo de ratas prenhes não tratadas.

a)

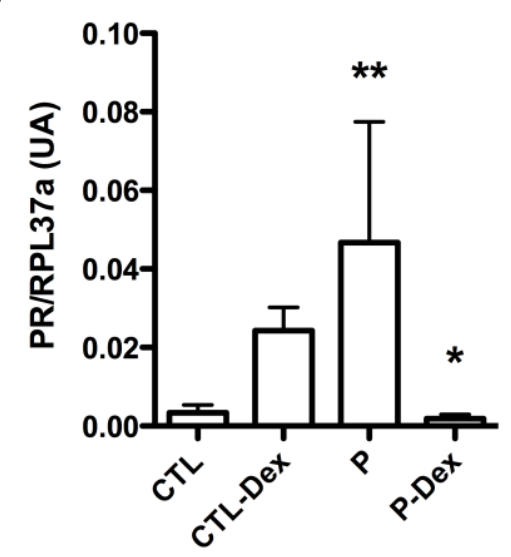

b)

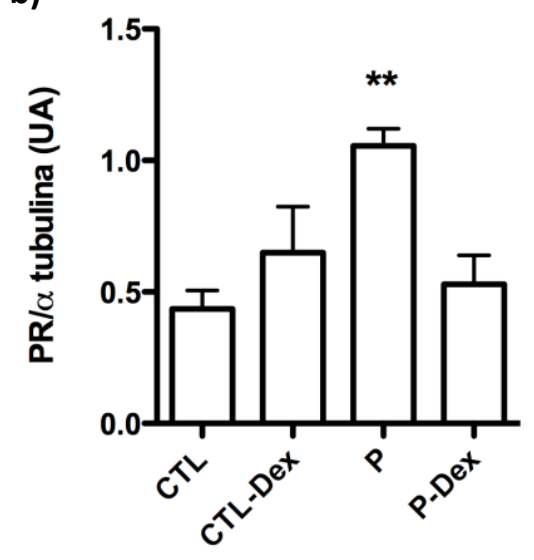

Figura 13. Expressão gênica (a) e conteúdo proteico (b) do receptor de progesterona (PR) em ilhotas de ratas CTL, CTL-Dex, P e P-Dex, obtidos no $20^{\circ}$ dia de gestação. ${ }^{*} p<0,05$ P-Dex vs. P, ${ }^{* *} p<0,05$ P vs. CTL. $\mathrm{n}=5$ 10 animais. 


\section{DISCUSS ̃̃O}


Numerosos estudos sobre o excesso de glicocorticoide na gravidez e programação metabólica têm como foco a síndrome metabólica tardia devido ao desenvolvimento intrauterino inadequado da prole ${ }^{79-81}$, mas o impacto do excesso de glicocorticoides pré-natal sobre a fisiologia materna tem sido negligenciado. Desse modo hipotetizou-se que o metabolismo energético materno também poderia sofrer efeitos tardios.

Como já foi descrito em seus descendentes, as mães tratadas com DEXA durante o último terço da gravidez também desenvolve intolerância à glicose em longo prazo, associada à deficiência na secreção de insulina estimulada por glicose. Além disso, foi demonstrado que a regulação positiva da família dos miR-29 é um processo epigenético mantido juntamente com a intolerância à glicose tardia, consistindo assim em um mecanismo candidato à falência das células beta pancreáticas em longo prazo.

O tratamento com DEXA via água de beber reduziu o peso corporal de ratas virgens e o ganho de peso corporal materno durante o último terço da gravidez, atestando a eficácia do protocolo experimental. Além disso, a intolerância à glicose e hiperglicemia aleatória observada em ratas não grávidas imediatamente após o tratamento são características fenotípicas da terapia com DEXA ${ }^{82}$. A recuperação da homeostasia glicídica em ratas virgens tratadas com DEXA não foi um fenômeno inesperado, tendo em vista que já foi previamente demonstrado que, em ratos machos, a intolerância à glicose e a disfunção das células beta do pâncreas induzida por DEXA são revertidas após a descontinuação do tratamento ${ }^{83}$. Curiosamente, o aparecimento de intolerância à glicose e maior ganho de peso em ratas grávidas tratadas com DEXA foi um fenômeno tardio e sustentado.

Processos epigenéticos são os candidatos principais para mecanismos que possam de forma estável, modular a expressão do gene envolvido na programação metabólica. Na busca pelo mecanismo envolvido no aparecimento tardio da intolerância à glicose em ratas grávidas tratadas com DEXA, foi rastreado possíveis alterações na expressão de miRNA. A hipótese baseou-se (i) em um estudo prévio que demonstrou que glicocorticoide sintético pode regular a expressão de miRNA em vários tipos de células ${ }^{84}$, (ii) no papel central dos miRNAs na função das células beta do pâncreas ${ }^{85,86} \mathrm{e}$, (iii) em uma triagem dos efeitos de DEXA na expressão de miRNA em ilhotas pancreáticas .

A escolha da família miR-29 para uma análise mais aprofundada ocorreu devido à sua relevância na regulação da função das células beta pancreáticas e de sua manutenção ${ }^{77,87,88,89}$. Além disso, observou-se no rastreamento de miRNA que todos os membros desta família foram regulados por DEXA. Os miR-29 tem sido amplamente estudados por serem desregulados em vários processos, tais como tumorigênese ${ }^{90}$, fibrose de órgãos / tecidos ${ }^{91,92}$, 
senescência $^{93,94}$, e regulação da matriz extracelular ${ }^{95}$. A multiplicidade das ações dos miR-29 ocorre devido a uma característica comum destes pequenos RNAs, cada miRNA pode regular centenas de genes e cada gene pode ser regulado por vários miRNAs ${ }^{96}$. Esta característica resulta em uma complexa regulação pós-transcricional da expressão gênica, dependente do tipo celular e contexto específico de resposta.

Já foi demonstrado que, tanto em ilhotas pancreáticas como em células de insulinoma, a superexpressão de miR-29 provoca prejuízo na secreção de insulina estimulada por glicose e apoptose das células beta ${ }^{87,89}$. Tais relatos demonstraram que citocinas pró-inflamatórias e níveis elevados de glicose regulam positivamente a expressão dos miR-29, levando à disfunção das células beta pancreáticas. Os efeitos em longo prazo observados em ratas grávidas tratadas com DEXA estão de acordo com estes estudos anteriores. A ausência de disfunção das células beta imediatamente após o tratamento com DEXA poderia ser reflexo de um efeito limítrofe dos glicocorticoides sintéticos na fisiologia materna, como pode ser observado na glicemia aleatória e nos ensaios de tolerância à glicose. Sabe-se que glicocorticoides inibem a inflamação por inibição da atividade de NFkB, uma molécula de sinalização central de citocinas pró-inflamatórias ${ }^{97}$, o que poderia contra-regular o remodelamento morfofuncional característico da transição gestação-lactação.

Ratas não grávidas tratadas com DEXA apresentaram regulação negativa em curto prazo de miR-29a/c nas ilhotas pancreáticas. A supressão de miR-29a induzida por DEXA já foi descrita em outros tecidos ${ }^{98}$. Por outro lado, o miR-29c tem sido sugerido como um miRNA regulado no diabetes ${ }^{99}$.

Na busca por um mecanismo que poderia explicar a expressão prolongada dos miR-29 e do início tardio de prejuízo na homeostasia glicídica, foi investigada a expressão e a atividade de p53, um fator de transcrição que induz uma grande variedade de respostas citostáticos ou citotóxicos para tensões intrínsecas e exógenos, que resultam em parada do ciclo celular, a reparação do DNA, a apoptose ou senescência ${ }^{100}$ e regulação dos miR-29 $9^{94}$. Diferentes vias de sinalização intracelular convergem para p53 e resultam em regulação diferencial de seus alvos. Devido à sua diversidade funcional e sua importância na sobrevida celular, a expressão e a atividade de p53 são fortemente reguladas por meio de retroalimentação positiva e negativa ${ }^{101}$. Estudos recentes têm mostrado que a relação entre p53 e miRNAs envolve tanto a regulação da transcrição e/ou maturação de miRNAs por p53 como o controle do conteúdo e da atividade de p53 por miRNA ${ }^{93}$. Dentre estes eventos, já foi demonstrado que os miR-29 podem regular os reguladores da $\mathrm{p} 53^{101,102}$. 
Os resultados aqui apresentados não nos permite concluir se p53 é responsável pela duradoura expressão dos miR-29, ou se os níveis elevados dos miR-29 mantém a expressão p53. No entanto, o aumento de mRNA de PUMA, um gene classicamente regulado por p53 ${ }^{75}$, indica que a elevada expressão de p53 em ratas grávidas tratadas com DEXA resulta em maior atividade deste fator de transcrição. Assim, a retroalimentação positiva poderia estar envolvida na regulação sustentada p53/PUMA/miR29.

O aumento de miR-29 ${ }^{89}$ e de PUMA ${ }^{103,104}$ foram previamente associados a apoptose de células beta pancreáticas. Neste trabalho não foi evidenciada alteração relevante na morfologia do pâncreas, que pode ser devido ao período de investigação, uma vez que a morfologia do pâncreas foi analisada somente em G20. Assim o processo apoptótico poderia ocorrer ao longo do período pós desmame até a adaptação completa do pâncreas.

$\mathrm{Na}$ medida em que a secreção de insulina estimulada por glicose foi significantemente alterada pelo tratamento com DEXA, centramos o estudo na avaliação de proteínas da maquinaria exocitótica, que é um alvo bem reconhecido de miRNAs ${ }^{33,34,105}$. Sintaxina-1a (Stx-1a) é uma t-SNARE envolvida na exocitose da insulina. Tanto em roedores como em seres humanos, a diminuição da expressão de Stx-1a prejudica a secreção de insulina estimulada por glicose ${ }^{75,76}$. Além disso, um estudo recente demonstrou que o miR-29a regula diretamente o gene da Stx-1a na região $3^{\prime} \mathrm{UTR}^{77}$. Em nosso estudo verificamos que a diminuição dos níveis de proteína Stx-1a acompanha o prejuízo tardio na secreção de insulina estimulada por glicose em ratas prenhes tratadas com DEXA na gestação. Além disso, o aumento na expressão dos miR-29 está associado à regulação gênica negativa de Stx-1a e à diminuição da secreção de insulina estimulada por glicose in vivo. Desse modo, o mecanismo pelo qual ocorre falha na secreção de insulina em longo prazo após o tratamento com DEXA na gestação de fato envolve a maquinaria exocitótica.

Uma vez descrito o fenômeno de alteração epigenética do pâncreas endócrino materno pelo excesso gestacional de glicocorticoides, a primeira pergunta aparente foi qual ou quais fatores que, quando associados ao meio interno gestacional, promovem alterações funcionais permanentes? Frente ao desafio de investigar o complexo meio interno da gestação, iniciamos esta etapa do estudo pela análise da resposta inflamatória na ilhota de ratas prenhes tratadas ou não com DEXA.

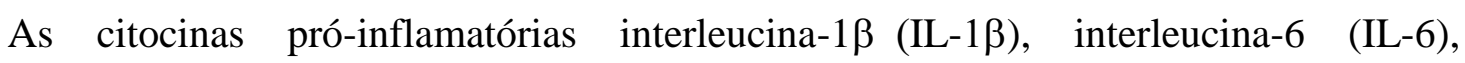
interleucina-8 (IL-8) e o fator $\alpha$ de necrose tumoral (TNF- $\alpha$ ) tem função evidente no parto a termo $^{78,106,107}$. Tais citocinas são pleiotrópicas em termos de desencadear uma resposta a 
partir de uma quantidade inumerável de células, muitas das quais são autócrinas ${ }^{108}$. Elas também são pleiotrópicas em desenhar um número de diferentes respostas celulares, por exemplo, TNF- $\alpha$ estimula tanto a sobrevivência como a apoptose ${ }^{109}$. Entretanto, as três citocinas estimulam a translocação do fator de transcrição nuclear kappa (NFkB) para o núcleo e, subsequentemente da transcrição de muitos mediadores de inflamação, incluindo cada uma dessas três citocinas ${ }^{110,111}$.

O desencadeamento de apoptose de células beta parece ser regulado por sinais intracelulares semelhantes, por exemplo, por NFkB e STAT- $1^{112}$, ocorrendo em paralelo à intensa inflamação. A exposição de células beta à citocinas inflamatórias induz o estresse de retículo (ER), o que leva ao acúmulo de proteínas deformadas no retículo endoplasmático (RE) desencadeando a resposta do complexo UPR ${ }^{113-115}$, com o objetivo de amenizar o ER e restaurar a homeostase por meio da diminuição da chegada de novas proteínas, aumentando a quantidade de chaperonas, a extrusão e a degradação de proteínas mal dobradas de forma irreversível. Quando ocorre falha nesse mecanismo a apoptose é desencadeada ${ }^{115}$. Embora ainda não demonstrado, é plausível a hipótese de que o estado inflamatório do final da gestação participe do remodelamento funcional da ilhota pancreática pós-gestacional.

Em animais experimentais já está documentado que, na primeira semana pós-parto, as ilhotas pancreáticas apresentam aumento da apoptose e redução da taxa de proliferação celular $^{6,14,15}$. Estudos prévios conduzidos em nosso laboratório contribuíram para o entendimento deste fenômeno. Primeiro, demonstramos que a redução da taxa de proliferação da célula beta no pós-parto é dependente da redução da atividade das MAPK mitogênicas ERK1/2 ${ }^{15}$. Segundo, descrevemos um dos mecanismos responsáveis pela apoptose da célula $\beta$ materna no período pós-natal, mecanismo este dependente da ativação do estresse do retículo endoplasmático $(\mathrm{RE})^{14}$. A expressão de proteínas da via do estresse do RE que comprometem irreversivelmente a apoptose não aparece no final da gestação, mas sim como um evento tardio, i.e, no terceiro dia de lactação. Cabe aqui ressaltar que proteínas envolvidas na ativação do estresse do RE, como IRE1a e TRAF2 interagem com JNK e/ou IKK, promovendo sua ativação ${ }^{116}$. Na medida em que (i) a ativação de JNK é um ponto de convergência entre a via do estresse do RE e a via inflamatória ${ }^{116}$; (ii) não há alteração da via do estresse do RE no final da gestação, mas apenas durante a apoptose do período de lactação $^{14}$ e (iii) o desequilíbrio entre apoptose seguido de proliferação da célula $\beta$ no período pós-parto ${ }^{6}$ poderia comprometer permanentemente a renovação celular e resultar em falência 
precoce da secreção de insulina, avaliamos a ativação da JNK e do NFkB nas ilhotas de ratas prenhes tratadas ou não com DEXA.

NF-кB é um fator de transcrição chave associado à apoptose das células $\beta$ pancreáticas, em especial à relacionada ao $\mathrm{DM} 1^{117}$. Nossos resultados mostram aumento da fosforilação de JNK, aumento da fosforilação de IKK e de sua degradação, e aumento da

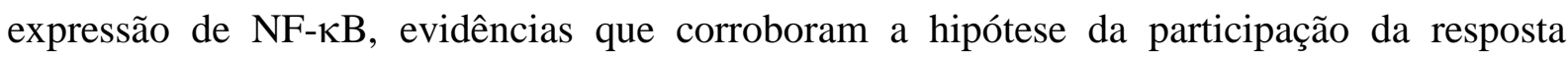
inflamatória no remodelamento funcional do pâncreas endócrino materno. A ausência de alteração de IKK pode ser devido à ativação de JNK independentemente de $\mathrm{IKK}^{116}$, ou a participação de diferentes isoformas de IKK na fosforilação e degradação de IKB. De fato, há evidências de que as citocinas pró-inflamatórias IL-1 $\beta$ e TNF- $\alpha$ não ativam a via do NFкB dependente de IKK $\alpha^{118}$.

Considerando que o foco central deste estudo é a gestação, a análise do perfil hormonal frente ao excesso de glicocorticoides não poderia ser negligenciada. Iniciamos pela quantificação de estrógeno e progesterona circulantes, na medida em que estes estão implicados na fisiologia da célula beta por efeito direto na secreção de insulina ${ }^{119,120}$ e na proliferação das células beta ${ }^{121,122,123}$. Mais recentemente, foi demonstrado que a progesterona induz a apoptose de células beta e de células de linhagem de insulinoma ${ }^{124}$. Outro efeito recentemente descrito das progestinas é a da redução da expressão de miR-29 em células tronco em câncer de mama ${ }^{125}$, achado que remete à nossa observação inicial de aumento da expressão dos miR-29 nas ilhotas das ratas prenhes tratadas com DEXA.

Em células neurais, a exposição à DEXA diminui a síntese de enzimas esteroidogênicas e de progesterona ${ }^{126}$. No presente estudo observamos redução na concentração plasmática de progesterona e de seu receptor nas ilhotas pancreáticas de ratas prenhes tratadas com DEXA. Desta forma, é possível que o excesso de GC no final da gestação exerça - além de sua ação anti-inflamatória - uma ação repressora da sinalização de progesterona na ilhota pancreática.

A região promotora dos miR-29 humanos contem múltiplos sítios de ligação de NFKB, que por sua vez promove a repressão da expressão destes miRNA ${ }^{127}$. Funcionalmente, membros da família miR-29 estão envolvidos com a promoção de apoptose ${ }^{128,129}$. Assim, a regulação positiva dos miR-29 mediada pela redução do $\mathrm{NFkB}$, associada à regulação negativa da sinalização de progesterona, são mecanismos candidatos ao provável prejuízo do remodelamento fisiológico (apoptose seguida de proliferação celular) das ilhotas pancreáticas no início da lactação. 
Evidências da presença de infiltrado inflamatório nas ilhotas de ratas prenhes, somado à estimulação da via da JNK, aumento de $\mathrm{NFkB}$ e da sinalização de progesterona, devem favorecer a apoptose da célula beta no pós-parto e, por conseguinte, a renovação celular. Por sua vez, a exposição à DEXA na gestação reduziu o infiltrado inflamatório, a ativação da via da JNK, a expressão de NFkB e os níveis de progesterona circulante e de seu receptor nas ilhotas de ratas G20. Os perfis de apoptose e proliferação celular, bem com de suas vias, ainda precisam ser analisados ao longo da lactação. 


\section{CONCLUS ÃO}


Dada a natureza de longa duração do comprometimento da função das células beta pancreáticas em ratas tratadas com DEXA na prenhez, fica evidente que o tratamento induziu alterações epigenéticas, provavelmente devido à modulação por DEXA do perfil hormonal e/ou inflamatório gestacional, responsável pela recuperação do metabolismo materno póslactação. O tratamento com DEXA no período gravídico modulou positivamente membros da família miRNA-29, que se mostrou associado ao desequilíbrio na homeostasia glicêmica devido à falha na maquinaria exocitótica de insulina em longo prazo. $\mathrm{O}$ aumento sustentado da expressão dos miR-29 induzido por DEXA - quer pelo aumento de p53 ou pela redução de NFkB -, associado à redução da sinalização da progesterona, são mecanismos candidatos ao prejuízo no processo de remodelamento da ilhota pancreática na fase final da gestação. 


\section{REFER $\hat{E} \mathcal{N C I} \mathcal{A S}$}


1. Leturque A, Ferre P, Burnol AF, Kande J, Maulard P, Girard J. Glucose utilization rates and insulin sensitivity in vivo in tissues of virgin and pregnant rats. Diabetes. 1986;35:172-7.

2. Ferre P, Burnol AF, Leturque A, Terretaz J, Penicaud L, Jeanrenaud B, et al. Glucose utilization in vivo and insulin-sensitivity of rat brown adipose tissue in various physiological and pathological conditions. Biochem J. 1986;233:249-252.

3. Catalano PM, Tyzbir ED, Roman NM, Amini SB, Sims EA. Longitudinal changes in insulin resistance and insulin release in non-obese pregnant women. Am J Obstet Gynecol. 1991;165:1667-71.

4. Rossi G, Sherwin RS, Penzias AS, Lapaczewski P, Jacob RJ, Shulman GI, et al. Temporal changes in insulin resistance and secretion in 24-h-fasted conscious pregnant rats. Am J Physiol. 1993;265:E845-851.

5. Bender HS, Chickering WR. Pregnancy and diabetes: the maternal response. Life Sci. 1985;37:1-9.

6. Scaglia L, Smith FE, Bonner-Weir S. Apoptosis contributes to the involution of beta cell mass in the post partum rat pancreas. Endocrinology. 1995;136:5461-8.

7. Akerman F, Lei ZM, Rao CV. Human umbilical cord and fetal membranes coexpress leptin and its receptor genes. Gynecological Endocrinol. 2002;16:299-306.

8. WeinhausAJ, Bhagroo NV, Brelje TC, Sorenson RL. Dexamethasone counteracts the effect of prolactin on islet function: implications for islet regulation in late pregnancy. Endocrinology. 2000;141:1384-93.

9. Hennen G, Frankenne F, Closset J, Gomez F, Pirens G, Khayat N. A human placental GH: increasing levels during second half of pregnancy with pituitary GH suppression as revealed by monoclonal antibody radioimmunoassay. Int. J. Fertil. 1985;30:27-33.

10. Fant M, Munro H, Moses AC. An autocrine/paracrine role for insulin-like growth factors in the regulation of human placental growth. J Clin Endocrinol Metab. 1986;63:499-505.

11. Shibasaki T, Odagiri E, Shizume K, Ling N. Corticotropin-releasing factor-like activity in human placental extracts. J Clin Endocrinol Metab 1982,55:384-6.

12. Anhê GF, Nogueira TC, Nicoletti-Carvalho JE, Lellis-Santos C, Barbosa HC, CipollaNeto J, et al. Signal transducer and activator of transcription 3-regulated sarcoendoplasmic reticulum $\mathrm{Ca}^{2+}$-ATPase 2 expression by prolactin and glucocorticoids is involved in the adaptation of insulin secretory response during the peripartum period. J Endocrinol. 2007;195:17-27.

*De acordo com:

International Committee of Medical Journal Editors. [Internet]. Uniform requirements for manuscripts submitted to Biomedical Journal: sample references. [updated 2011 Jul 15]. Available from: http://www.icmje.org 
13. Lellis-Santos C, Sakamoto LH, Bromati CR, Nogueira TC, Leite AR, Yamanaka TS, et al. The regulation of Rasd1 expression by glucocorticoids and prolactin controls peripartum maternal insulin secretion. Endocrinology. 2012;153:3668-78.

14. Bromati CR, Lellis-Santos C, Yamanaka TS, Nogueira TC, Leonelli M, Caperuto LC, et al. UPR induces transient burst of apoptosis in islets of early lactating rats through reduced AKT phosphorylation via ATF4/CHOP stimulation of TRB3 expression. Am J Physiol Regul Integr Comp Physiol. 2011;300:R92-100.

15. Nicoletti-Carvalho JE, Lellis-Santos C, Yamanaka TS, Nogueira TC, Caperuto LC, Leite AR, et al. MKP-1 mediates glucocorticoid-induced ERK1/2 dephosphorylation and reduction in pancreatic-cell proliferation in islets from early lactating mothers. AmJPhysiol Endocrinol Metab. 2010;299:E1006-15.

16. Lee RC, Feinbaum RL, Ambros V. The C. elegans heterochronic gene lin-4 encodes small RNAs with antisense complementarity to lin-14. Cell.1993;75:843-54.

17. Tanzer A, Stadler PF. Evolution of microRNAs. Methods Mol Biol. 2006;342:335-50.

18. Krutzfeldt J, Stoffel M. MicroRNAs: a new class of regulatory genes affecting metabolism. Cell Metab. 2006;4:9-12.

19. Sigma. [Cited 2014 Oct 14]. Available from: http://www.sigmaaldrich.com/lifescience/functional-genomics-and rnai/mirna/learning-center.mirna-introduction.html.

20. Mineno J, Okamoto S, Ando T, Sato M, Chono H, Izu H, et al. The expression profile of microRNAs in mouse embryos. Nucleic Acids Res. 2006;34:1765-71.

21. Park JK, Liu X, Strauss TJ, McKearin DM, Liu Q. The miRNA pathway intrinsically controls self renewal of Drosophila germline stem cells. Curr. Biol. 2007;17:533-8.

22. van Rooij E, Sutherland LB, Qi X, Richardson JA, Hill J, Olson EN. Control of stressdependent cardiac growth and gene expression by a microRNA. Science.2007;316:575-9.

23. Kim J, Inoue K, Ishii J, Vanti WB, Voronov SV, Murchison E, et al. A MicroRNA feedback circuit in midbrain dopamine neurons. Science.2007;317:1220-4.

24. Niu QW, Lin SS, Reyes JL, Chen KC, Wu HW, Yeh SD, et al. Expression of artificial microRNAs in transgenic Arabidopsis thaliana confers virus resistance. Nat. Biotechnol. 2006;24:1420-8.

25. Wang Y, Lee CG. MicroRNA and cancer--focus on apoptosis. J Cell Mol Med. 2009;13:12-23.

26. Poy MN, Spranger M, Stoffel M. microRNAs and the regulation of glucose and lipid metabolism. Diabetes Obes Metab. 2007;9:67-73. 
27. John B, Enright AJ, Aravin A, Tuschl T, Sander C, Marks DS. Human MicroRNA targets. PLoS Biol. 2004;2:e363.

28. Friedman RC, Farh KK, Burge CB, Bartel DP. Most mammalian mRNAs are conserved targets of microRNAs. Genome Res. 2009;19:92-105.

29. Griffiths-Jones S, Saini HK, van Dongen S, Enright AJ. miRBase: Tools for microRNA genomics. Nucleic Acids Res. 2008;36:D154-8.

30. Berezikov E, Cuppen E, Plasterk RH. Approaches to microRNA discovery. Nat. Genet. 2006;38:S2-7.

31. Poy MN, Eliasson L, Krutzfeld, J, Kuwajima S, Ma X, Macdonald PE, et al. A pancreatic islet-specific microRNA regulates insulin secretion. Nature.2004;432:22630 .

32. Baroukh N, Ravier MA, Loder MK, Hill EV, Bounacer A, Scharfmann R, et al. MicroRNA-124a regulates Foxa2 expression and intracellular signaling in pancreatic beta-cell lines. J Biol Chem. 2007;282:19575-88.

33. Plaisance V, Abderrahmani A, Perret-Menoud V, Jacquemin P, Lemaigre F, Regazzi R. MicroRNA-9 controls the expression of Granuphilin/Slp4 and the secretory response of insulin-producing cells. J Biol Chem. 2006;281:26932-42.

34. Lovis P, Gattesco S, Regazzi R. Regulation of the expression of components of the exocytotic machinery of insulin-secreting cells by microRNAs. Biol Chem. 2008a;389:305-12.

35. Tang X, Muniappan L, Tang G, Ozcan S. Identification of glucose-regulated miRNA from pancreatic beta cells reveals a role for miR-30d in insulin transcription. RNA. 2009; 15:287-93.

36. Hennessy E, Clynes M, Jeppesen PB, O'Driscoll L. Identification of microRNAs with a role in glucose stimulated insulin secretion by expression profiling of MIN6 cells. Biochem Biophys Res Commun. 2010;396:457-62.

37. Lovis P, Roggli E, Laybutt DR, Gattesco S, Yang JY, Widmann C, et al. Alterations in microRNA expression contribute to fatty acid-induced pancreatic beta-cell dysfunction. Diabetes. 2008b;57:2728-36.

38. Li Y, Xu X, Liang Y, Liu S, Xiao H, Li F, et al. miR-375 enhances palmitate-induced lipoapoptosis in insulin-secreting NIT-1 cells by repressing myotrophin (V1) protein expression. Int J Clin Exp Pathol. 2010;3:254-64.

39. Bodor N, Buchwald P. Corticosteroid design for the treatment of asthma: structural insights and the therapeutic potential of soft corticosteroids.Curr Pharm Des. 2006;12:3241-60.

40. Saklatvala J. Glucocorticoids: do we know how they work? Arthritis Res. 2002;4:14650 . 
41. Burén J, Liu HX, Jensen J, Eriksson JW. Dexamethasoneimpairs insulin signaling and glucose transport by depletionof insulin receptor substrate-1, phosphatidylinositol 3kinase and protein kinase $\mathrm{B}$ in primary cultured rat adipocytes. Eur $\mathbf{J}$ Endocrinol. 2002;146:419-29.

42. Olefsky JM, Kimmerling G. Effects of glucocorticoidson carbohydrate metabolism. Am J Med Sci. 1976;271:202-10.

43. Ruzzin J, Wagman AS, Jensen J. Glucocorticoidinducedinsulin resistance in skeletalmuscles: defects in insulin signaling and the effects of a selective glycogen synthase kinase-3 inhibitor.Diabetologia. 2005;48:2119-30.

44. Schäcke H, Döcke WD, Asadullah K. Mechanismsinvolved in the side effects of glucocorticoids. Pharmacol Ther. 2002;96:23-43.

45. Larsson H, Ahrén B. Insulin resistant subjects lack isletadaptation to short-term dexamethasone-induced reduction in insulin sensitivity.Diabetologia. 1999;42:936-43.

46. Novelli M, Pocai A, Chiellini C, Maffei M, Masiello P. Free fatty acids as mediators of adaptive compensatoryresponses to insulin resistance in dexamethasone-treated rats. Diabetes Metab Res Rev. 2008;24:155-64.

47. Rafacho A, Abrantes JL, Ribeiro DL, Paula FM, Pinto ME, Boschero AC, et al. Morphofunctionalalterations in endocrine pancreas of short- and long-term dexamethasone-treated rats.Horm Metab Res. 2011;43(4):275-81.

48. Rafacho A, Giozzet VA, Boschero AC, Bosqueiro JR.. Bosqueiro. Functional alterations in endocrine pancreas of rats withdifferent degrees of dexamethasoneinduced insulin resistance. Pancreas. 2008;36:284-93.

49. Wajngot A, Giacca A, Grill V, Vranic M, Efendic S. Thediabetogenic effects of glucocorticoids are more pronounced in low- than in high-insulin responders. Proc Natl Acad Sci U S A. 1992;89:6035-9.

50. van Raalte DH, Ouwens DM, Diamant M. Novel insights into glucocorticoidmediated diabetogenic effects: towards expansion of therapeutic options? Eur J Clin Invest. 2009;39:81-93.

51. Nold JL, Georgieff MK. Infants of diabetic mothers. Pediatr Clin North Am. 2004;51: 619-37.

52. Simmons R, Flozak A, Ogata E. Glucose regulates glut 1 function and expression in fetal rat lung and muscle in vitro. Endocrinology. 1993;132:2312-8.

53. Humbel RE. Insulin-like growth factors I and II. Eur J Biochem. 1990;190:445-62.

54. Andrews RC, Walker BR. Glucocorticoids and insulin resistance: old hormones, new targets. Clin Sci (Lond). 1999;96:513-23. 
55. Low SC, Chapman KE, Edwards CR, Seckl JR. 'Liver-type' 11 beta- hydroxysteroid dehydrogenase cDNA encodes reductase but not dehydrogenase activity in intact mammalian COS-7 cells. J Mol Endocrinol. 1994;13:167-74.

56. Voice MW, Seckl JR, Edwards CR, Chapman KE.11 beta-hydroxysteroid dehydrogenase type 1 expression in 2S FAZA hepatoma cells is hormonally regulated: a model system for the study of hepatic glucocorticoid metabolism. Biochem $\mathrm{J}$. 1996;317:621-5.

57. Brown RW, Chapman KE, Edwards CR, Seckl JR. Human placental 11 betahydroxysteroid dehydrogenase: evidence for and partial purification of a distinct NAD-dependent isoform. Endocrinology. 1993;132:2614-21.

58. Mangelsdorf DJ, Thummel C, Beato M, Herrlich P, Schütz G, Umesono K, et al. The nuclear receptor superfamily: the second decade. Cell. 1995;83:835-9.

59. Nelson GM, Prapapanich V, Carrigan PE, Roberts PJ, Riggs DL, Smith DF. The heat shock protein 70 cochaperone hip enhances functional maturation of glucocorticoid receptor. Mol Endocrinol. 2004;18:1620-30.

60. Pratt WB, Morishima Y, Murphy M, Harrell M. Chaperoning of glucocorticoid receptors. Handb Exp Pharmacol. 2006;172:111-38.

61. Ismaili N, Garabedian MJ. Modulation of glucocorticoid receptor function via phosphorylation. Ann N Y Acad Sci. 2004;1024:86-101.

62. Chen DY, Bambah-Mukku D, Pollonini G. Glucocorticoid receptors recruit the CaMKII $\alpha$-BDNF-CREB pathways to mediate memory consolidation. Nat Neurosci. 2012;15:1707-14.

63. Ratman D, Vanden Berghe W, Dejager L, Libert C, Tavernier J, Beck IM et al. How glucocorticoid receptors modulate the activity of other transcription factors: a scope beyond tethering. Mol Cell Endocrinol. 2013;380:41-54.

64. Engblom D, Kornfeld JW, Schwake L, Tronche F, Reimann A, Beug H, et al. Direct glucocorticoid receptor-Stat5 interaction in hepatocytes controls body size and maturation-related gene expression. Genes Dev. 2007;21:1157-62.

65. Rafacho A, Ortsäter H, Nadal A, Quesada I. Glucocorticoid treatment and endocrine pancreas function: implications for glucose homeostasis, insulin resistance and diabetes. J Endocrinol. 2014;223:R49-62.

66. Kahn SE. The relative contributions of insulin resistance and beta-cell dysfunction to the pathophysiology of Type 2 diabetes. Diabetologia. 2003;46:3-19.

67. Poitout V, Amyot J, Semache M, Zarrouki B, Hagman D, Fontés G. Glucolipotoxicity of the pancreatic beta cell.Biochim Biophys Acta. 2010;1801:289-98.

68. Steil GM, Trivedi N, Jonas JC, Hasenkamp WM, Sharma A, Bonner-Weir S, et al. Adaptation of $\beta$ - cell mass to substrate oversupply: enhanced function with normal 
gene expression. Am J Physiol Endocrinol Metab. 2001;280:E788-96.

69. Bordin S, Boschero AC, Carneiro EM, Atwater I. Ionic mechanisms involved in the regulation of insulin secretion by muscarinic agonists. J Membr Biol. 1995;148:17784.

70. Lowry OH, Rosebrough NJ, Farr AL, Randall RJ. Protein measurement with the Folin phenol reagent. J Biol Chem 1951;193:265-75.

71. Garfin DE. One-Dimensional Gel Eletrophoresis. Methods Enzymol. 1990;182:42541.

72. Timmons TM, Dunbar B. Protein Blotting an Immunodetection. Methods Enzymol 1990;182:679-88.

73. Krueger NJ, Hammondo JBW. Immunodetection of proteins on "Western" blots using 1251 labeled protein A. Methods Mol. Biol. 1988;3:409-17.

74. Nakano K, Vousden KH. PUMA, a novel proapoptotic gene, is induced by p53. MolCell. 2001;7:683-94.

75. Nagamatsu S, Nakamichi Y, Yamamura C, Matsushima S, Watanabe T, Ozawa S, et al. Decreased expression of t-SNARE, syntaxin 1, andSNAP-25 in pancreatic betacells is involved in impaired insulin secretion fromdiabetic GK rat islets: restoration of decreased t-SNARE proteins improves impaired insulin secretion. Diabetes. 1999;48: 2367-73.

76. Ostenson CG, Gaisano H, Sheu L, Tibell A, Bartfai T. Impaired gene and protein expression of exocytotic soluble N-ethylmaleimide attachment protein receptor complex proteins in pancreatic islets of type 2 diabetic patients. Diabetes. 2006;55: 435-568.

77. Bagge A, Dahmcke CM, Dalgaard LT. Syntaxin-1a is a direct target of miR-29a in insulin-producing b-cells. Horm Metab Res. 2013;45:463-6.

78. Christiaens I, Zaragoza DB, Guilbert L, Robertson SA, Mitchell BF, Olson DM. Inflammatory processes in preterm and term parturition. $\mathrm{J}$ Reprod Immunol. 2008;79(1):50-7.

79. Ravelli AC, van der Meulen JH, Michels RP, Osmond C, Barker DJ, Hales CN, et al. Glucose tolerance in adults after prenatal exposure to famine. Lancet. 1998;351:173-7.

80. Nyirenda MJ, Lindsay RS, Kenyon CJ, Burchell A, R. Seckl JR. Glucocorticoid exposure in late gestation permanently programs rat hepatic phosphoenolpyruvate carboxykinase and glucocorticoid receptor expression and causes glucose intolerance in adult offspring. J Clin Invest. 1998;101:2174-81.

81. Martin-Gronert MS, Ozanne SE. Experimental IUGR and later diabetes. J Intern Med. 2007;261:437-52. 
82. Owen OE, Cahill GF Jr. Metabolic effects of exogenous glucocorticoids in fasted man. J Clin Invest. 1973;52:2596-605.

83. Rafacho A, Quallio S, Ribeiro DL, Taboga SR, Paula FM, Boschero AC, et al. The adaptive compensations in endocrine pancreas from glucocorticoid-treated rats are reversible after the interruption of treatment. Acta Physiol (Oxf). 2010;200:223-35.

84. Sionov RV. MicroRNAs and Glucocorticoid-Induced Apoptosis in Lymphoid Malignancies. ISRN Hematol. 2013:348212.

85. Fernandez-Valverde SL, Taft RJ, Mattick JS. MicroRNAs in b-Cell Biology, Insulin Resistance, Diabetes and Its Complications. Diabetes. 2011;60:1825-31.

86. Jacovetti C, Regazzi R. Compensatory $\beta$-cell mass expansion. A big role for a tiny actor. Cell Cycle. 2013;12:197-8.

87. Bagge A, Clausen TR, Larsen S, Ladefoged M, Rosenstierne MW, Larsen L, et al. MicroRNA-29a is up-regulated in beta-cells by glucose and decreases glucosestimulated insulin secretion. Biochem Biophys Res Commun. 2012;426:266- 72.

88. Pullen TJ, Xavier GS, Kelsey G, Rutter GA. miR-29a and miR-29b contribute to pancreatic b-cell-specific silencing of Monocarboxylate transporter 1 (Mct1). Mol Cell Biol. 2011;3182-94.

89. Roggli E, Gattesco S, Caille D, Briet C, Boitard C, Meda P, et al. Changes in microRNA expression contribute to pancreatic $\beta$-cell dysfunction in prediabetic NOD mice. Diabetes. 2012;61:1742-51.

90. Wang Y, Zhang X, Li H, Yu J, Ren X. The role of miRNA-29 family in cancer. Eur J Cell Biol. 2013;92:123-8.

91. He Y, Huang C, Lin X, Li J. MicroRNA-29 family, a crucial therapeutic target for fibrosis diseases. Biochimie. 2013;95:1355-9.

92. Roderburg C, Urban GW, Bettermann K, Vucur M, Zimmermann H, Schmidt S, et al. Micro-RNA profiling reveals a role for miR-29 in human and murine liver fibrosis. Hepatology. 2011;53:209-18.

93. Martinez I, Almstead LL, DiMaio D. MicroRNAs and senescence. Aging. 2011;3:778.

94. Ugalde AP, Ramsay AJ, Rosa J, Varela I, Marino G, Cadinanos J, et al. Aging and chronic DNA damage response activate a regulatory pathway involving miR-29 and p53. EMBO J. 2011;30:2219-32.

95. Hubmacher D, Apte SS. The biology of the extracellular matrix: novel insights. Curr Opin Rheumatol. 2013;25:65-70.

96. Krek A, Grun D, Poy MN, Wolf R, Rosenberg L, Epstein EJ, et al. Combinatorial microRNA target predictions. Nat Genet. 2005;37:495-500. 
97. Murphy SH, Suzuki K, Downes M, Welch GL, Jesus P, Miraglia LJ, et al. Tumor suppressor protein (p)53, is a regulator of NF- $\mathrm{BB}$ repression by the glucocorticoid receptor. Proc Natl Acad Sci U S A. 2011;108:17117-22.

98. Wang FS, Chung PC, Lin CL, Chen MW, Ke HJ, Chang YH, et al. MicroRNA-29a protects against glucocorticoid-induced bone loss and fragility in rats by orchestrating bone acquisition and resorption. Arthritis Rheum. 2013;65:1530-40.

99. Long J, Wang Y, Wang W, Chang BHJ, Danesh FR. MicroRNA-29c is a signature microRNA under high glucose conditions that targets Sprouty Homolog 1, and its in vivo knockdown prevents progression of diabetic nephropathy. J Biol Chem. 2011;286:11837-48.

100. Vousden KH, Prives C. Blinded by the light: The growing complexity of p53. Cell. 2009;137:413-31.

101. Jones M, Lal A. MicroRNAs, wild-type and mutant p53: more questions than answers. RNA Biol. 2012;9:781-91.

102. Park SY, Lee JH, Ha M, Nam JW, Kim VN. miR-29 miRNAs activate p53 by targeting p85 alpha and CDC42. Nat Struct Mol Biol. 2009;16:23-9.

103. Gurzov EN, Germano CM, Cunha DA, Ortis F, Vanderwinden JM, Marchetti P, et al. p53 up-regulated modulator of apoptosis (PUMA) activatio contribute to pancreatic $\beta$-cell apoptosis induced by proinflammatory cytokines and endoplasmic reticulum stress. J Biol Chem. 2010;285:19910-20.

104. Meares GP, Dominique Fontanilla D, Broniowska KA, Andreone T, Lancaster JR Jr, Corbett JA. Differential responses of pancreatic b-cells to ROS and RNS.Am J Physiol Endocrinol Metab. 2013;67:E614-22.

105. Esguerra JLS, Bolmeson C, Cilio CM, Eliasson L. Differential Glucose- Regulation of MicroRNAs in Pancreatic Islets of Non-Obese Type 2 Diabetes Model GotoKakizaki Rat. PLoS One. 2011;6:e18613.

106. Goldenberg RL, Hauth JC, Andrews WW. Intrauterine infection and preterm delivery. N Engl J Med.2000;342:1500- 7.

107. Elliott CL, Loudon JA, Brown N, Slater DM, Bennett PR, Sullivan MH. IL-1beta and IL-8 in human fetal membranes: changes with gestational age, labor, and culture conditions. Am J Reprod Immunol. 2001;46:260-7.

108. Lucey DR, Clerici M, Shearer GM. Type 1 and type 2 cytokine dysregulation in human infectious, neoplastic and inflammatory diseases. Clin Microbiol Rev. 1996;9:532-2.

109. Baker SJ, Reddy EP. Modulation of life and death by the TNF receptor superfamily. Oncogene. 1998; 17:3261-70. 
110. Iwamoto GK, Konicek SA. Cytomegalovirus immediate early genes upregulate interleukin-6 gene expression. J Investig Med. 1997;45:175-82.

111. Malinin NL, Boldin MP, Kovalenko AV, Wallach D. MAP3K-related kinase involved in NF-kappaB induction by TNF, CD95 and IL-1. Nature. 1997;385:540-4.

112. Eizirik DL, Moore F, Flamez D, Ortis F. Use of a systems biology approach to understand pancreatic beta-cell death in type 1 diabetes. Biochem Soc Trans. 2008;36:321-7.

113. Dogusan Z, García M, Flamez D, Alexopoulou L, Goldman M, Gysemans C, et al. Double-stranded RNA induces pancreatic beta-cell apoptosis by activation of the TLR3 and IRF-3 pathways. Diabetes. 2008;57:1236-45.

114. Cardozo AK, Ortis F, Storling J, Feng YM, Rasschaert J, Tonnesen M, et al. Cytokines downregulate the sarcoendoplasmic reticulum pump $\mathrm{Ca}^{2+}$ ATPase $2 \mathrm{~b}$ and deplete endoplasmic reticulum $\mathrm{Ca}^{2+}$ leading to induction of endoplasmic reticulum stress in pancreatic beta-cells. Diabetes. 2005;54:452-61.

115. Eizirik DL, Cardozo AK, Cnop M.. The role for endoplasmic reticulum stress in diabetes mellitus. Endocr Rev. 2008;29:42-61.

116. Zhang K, Kaufman RJ. From endoplasmic-reticulum stress to the inflammatory response. Nature.2008;454:455-62.

117. Eizirik DL, Colli ML, Ortis F.The role of inflammation in insulitisand beta-cellloss in type 1 diabetes. Nat Rev Endocrinol. 2009;5:219-26.

118. Ortis F, Cardozo AK, Crispim D, Storling J,MandrupPoulsen T, Eizirik DL. Cytokine-induced proapoptotic gene expression in insulin-producing cells is related to rapid, sustained, and nonoscillatory nuclear factor-kappaB activation. Mol Endocrinol. 2006;20:1867-79.

119. Lenzen S, Bailey CJ. Thyroid hormones, gonadal and adrenocortical steroids and the function of the islets of Langerhans. Endocr Rev. 1984;5:411-34.

120. Straub SG, Sharp GW, Meglasson MD, De Souza CJ. Progesterone inhibits insulin secretion by a membrane delimited, non-genomic action. Biosci Rep. 2001;21(5):653-66.

121. Nieuwenhuizen AG, Schuiling GA, Liem SM, Moes H, Koiter TR, Uilenbroek JT. Progesterone stimulates pancreatic cell proliferation in vivo. Eur $\mathbf{J}$ Endocrinol. 1999;140:256-63.

122. Kawai M, Kishi K. Adaptation of pancreatic islet b-cells during the last third of pregnancy: regulation of $b$-cell function and proliferation by lactogenic hormones in rats. Eur J Endocrinol. 1999;141:419-25. 
123. Le May C, Chu K, Hu M, Ortega CS, Simpson ER, Korach KS, et al. Estrogen protect pancreatic beta-cells from apoptosis and prevent insulin-deficient diabetes mellitus in mice. Proc Natl Acad Sci U S A. 2006;103:9232-7.

124. Nunes VA, Portioli-Sanches EP, Rosim MP, Araujo MS, Praxedes-Garcia P, Valle $\mathrm{MM}$, et al. Progesterone induces apoptosis of insulin-secreting cells: insights into the molecular mechanism. J Endocrinol. 2014;221:273-84.

125. Cittelly DM, Finlay-Schultz J, Howe EN, Spoelstra NS, Axlund SD, Hendricks P, et al. Progestin suppression of miR-29 potentiates dedifferentiation of breast cancer cells via KLF4. Oncogene. 2013;32:2555-64.

126. Koibuchi F, Ritoh N, Aoyagi R, Funakoshi-Tago M, Tamura H. Dexamethasone suppresses neurosteroid biosynthesis via downregulation of steroidogenic enzyme gene expression in human glioma GI-1 cells.BiolPharm Bull. 2014;37(7):1241-7.

127. Wang H, Garzon R, Sun H, Ladner KJ, Singh R, Dahlman J, et al. NF-kappaB-YY1miR-29 regulatory circuitry in skeletal myogenesis and rhabdomyosarcoma. Cancer Cell. 2008;14:369-81.

128. Mott JL, Kobayashi S, Bronk SF, Gores GJ. mir-29 regulates Mcl-1 protein expression and apoptosis. Oncogene. 2007;26:6133-40.

129. Park SY, Lee JH, Ha M, Nam JW, Kim VN. miR-29 miRNAs activate p53 by targeting p85 alpha and CDC42. Nat Struct Mol Biol. 2009;16:23-9. 


\section{AP $\hat{\mathcal{E}} \mathcal{N D I C E S}$}


APÊNDICE A -Artigos publicados de 2011 a 2014

1. Gomes PR, Graciano MF, Pantaleão LC, Rennó AL, Rodrigues SC, Velloso LA, et al.Long-term disruption of maternal glucose homeostasis induced by prenatal glucocorticoid treatment correlates with miR-29 upregulation.Am J Physiol Endocrinol Metab. 2014;306:E109-20.

2. Rodrigues SC, Pantaleao LC, Nogueira TC, Gomes PR, Albuquerque GG, Nachbar RT, et al.Selective regulation of hepatic lipid metabolisAm J Physiol Regul Integr Comp Physiol. 2014 Aug 27. pii: ajpregu.00513.2013.

3. Ferreira DS, Amaral FG, Mesquita CC, Barbosa AP, Lellis-Santos C, Turati AO, et al. Maternal melatonin programs the daily pattern of energy metabolism in adult offspring. PLoS One. 2012;7:e38795. 
APÊNDICE B - Artigo submetido para publicação (em revisão)

1. Adriana R Leite, Fernando F Anhê, Priscilla M Silva, Gustavo J Santos, Camilo Lellis-Santos, Tatiane C Nogueira, Patricia R Gomes, Antonio C Boschero, Luciana C Caperuto, Gabriel F Anhe. Bone Morphogenetic Protein 9 potentiates glucosestimulated insulin secretion in neonatal rat islets via SMAD1-mediated GLUT2 expression. Molecular and Cellular Endocrinology. 